\title{
CONSUMPTION, DEBT AND PORTFOLIO CHOICE* Testing the Effect of Bankruptcy Law
}

\section{Andreas Lehnert}

Board of Governors of the

Federal Reserve System

Mail Stop 93

Washington DC, 20551

(202) 452-3325
Dean M. Maki

Putnam Investments

One Post Office Square

Boston MA, 02109

(617) 760-8616

Dean_Maki@putnaminv.com

Andreas.Lehnertefrb.gov

\section{This version:}

February 2002

February 20, 2002

*The views are expressed in this paper are ours alone and do not necessarily reflect those of the Board of Governors or its staff or Putnam Investments. We thank Darrel Cohen, Karen Dynan, Ronel Elul, Gary Engelhardt, David Laibson, Nick Souleles, Robert Townsend and seminar participants at Syracuse University, the NBER 2000 Summer Institute and the Federal Reserve Board. We received excellent research assistance from Sigurd Lund, Richard Sauoma and Marcin Stawarcz. Any remaining errors are our own responsibility. 



\title{
CONSUMPTION, DEBT AND PORTFOLIO CHOICE Testing the Effect of Bankruptcy Law
}

\begin{abstract}
Consumer bankruptcy laws, which vary across states and over time, permit debtors to keep assets below a statutory exemption while debts are forgiven. High exemptions distort household portfolio decisions and tempt households to default on debts; but they also provide a crude form of consumption insurance. We combine information on state-level bankruptcy laws with the Consumer Expenditure Survey from 1984-1999. We find that higher exemptions are associated with (1) Higher bankruptcy rates, (2) Households that are more likely to simultaneously hold low-return liquid assets and owe high-cost unsecured debt, and (3) Slightly better consumption insurance for renters and worse consumption insurance for homeowners.
\end{abstract}

Journal of Economic Literature classification numbers: H73, H31, K00, D1. Keywords: Bankruptcy law, household debt, portfolio puzzle, consumption. 



\section{Introduction}

In the United States, consumer (Chapter 7 and Chapter 13) bankruptcy is designed to provide debtors a "fresh start." After a household successfully files a Chapter 7 petition, its unsecured debts are erased, but it must forfeit any assets above an exemption level determined by law. Although the United States constitution specifically grants the Federal government the power to set national bankruptcy law, in practice these laws are mostly set by the individual states. ${ }^{1}$ State consumer bankruptcy laws vary most dramatically in generosity-i.e. the exemption levels above which households forfeit assets. Some state Chapter 7 bankruptcy codes are extremely generous, allowing households to keep an unlimited amount of assets after bankruptcy, while others are relatively stingy, allowing households to keep, for example, only $\$ 75$ in assets after bankruptcy.

Bankruptcy laws of this type provide households with a crude form of insurance. If households face the possibility that their non-capital income could dip to zero for an extended period, they would be unwilling to use unsecured debt unless somehow insured. Carroll (1992) uses the PSID to confirm that households do face such a risk, suggesting that in the absence of other forms of insurance, households would be less willing to use unsecured debt in states with less generous bankruptcy laws, although lenders would be more willing to extend unsecured debt in such states. Further, a household with relatively large debts would cut con-

\footnotetext{
${ }^{1}$ Article I, Section 8 of the U.S. constitution states "The Congress shall have the power ... [t]o establish a uniform rule of naturalization, and uniform laws on the subject of bankruptcies throughout the United States." For information on consumer bankruptcy laws outside the United States, see Alexopoulos and Domowitz (1998) and Ziegel (1997).
} 
sumption more in response to an income shock in less generous states.

At the same time, though, Chapter 7 bankruptcy laws distort households' portfolio choices. Households that file for bankruptcy are better off if they have assets right up to the exemption level set in law. They carry these assets with them into their post-bankruptcy life, while their debts (largely) vanish. Thus it is in their interest to simultaneously hold low-return liquid assets even while they have a significant amount of high-interest debt. Morrison (1999) and Bertaut and Haliassos (2001) have documented the existence of this anomaly using the Survey of Consumer Finances. Bertaut and Haliassos present evidence that the portfolio puzzle may be driven by self control, in which the household may be thought of as divided between two decision makers, a worker and a shopper. The worker chooses not to pay off the household's credit cards as a way to restrain the shopper. ${ }^{2}$

Finally, all else equal, households will be more likely to declare bankruptcy in states with more generous exemptions. Of course, lenders may react to prevailing bankruptcy laws by restricting credit to borrowers living in states with generous laws, so the net effect of bankruptcy law on bankruptcy rates may go in either direction.

To test these effects, we collected data on state personal bankruptcy exemptions, and other state-level information, from 1984-1999. We matched these data with household-level responses from the Consumer Expenditure Survey (CE) over the same period. The CE contains detailed information about households' consumption, along with some information about their geographic location, de-

\footnotetext{
${ }^{2}$ See also Laibson, Repetto, and Tobacman (1998) and Harris and Laibson (2001).
} 
mographic characteristics, finances, income, occupation, employment and health status. The CE asks in detail about holdings of different asset classes (for example, securities, checking accounts, saving accounts, U.S. savings bonds), and less detailed information about unsecured debt. We use this portfolio information to test whether households in generous bankruptcy law states are more likely to simultaneously hold low-return liquid assets and high-interest unsecured debt. We refer to this practice as as "borrowing to save."

The CE interviews the same household once per quarter for five quarters; the first interview is excluded from the public use microdata, but all other interviews are available. Thus it is possible to construct a short panel for each household, testing how consumption responds to shocks of various types. We use this information to test the insurance role of bankruptcy law.

We find: (1) bankruptcy rates are higher in states with higher bankruptcy exemptions; (2) households are more likely to borrow to save in states with generous laws; and (3) the consumption of renters is slightly less sensitive to income shocks in states with generous bankruptcy laws while, by contrast, the consumption of homeowners is slightly more sensitive to income shocks in states with generous bankruptcy laws.

The plan of this paper is as follows: in section 2 we briefly review the previous literature and the debate surrounding bankruptcy law, while in section 3 we provide a theoretical framework for our analysis. In section 4 we describe our data sources and the construction of the bankruptcy law database and generosity measures and in section 5 we present our results. Section 6 briefly concludes. 
An appendix provides the results from alternative specifications of our statistical models and further discussion of our dataset. All tables and figures are located at the end of the paper, following the references.

\section{The Bankruptcy Debate}

Much of the current debate over bankruptcy reform is prompted by the extremely high bankruptcy filing rate in the late 1990s. ${ }^{3}$ Little is known about why the bankruptcy rate has increased; for example, using a data set of credit card records, Gross and Souleles (1998) show that the increase in delinquency rates through the 1990s cannot be explained by observable factors; they posit a decrease in stigma during the decade as the cause.

\footnotetext{
${ }^{3}$ The bankruptcy rate also spiked in the first half of 2001. This most recent increase was likely a response to Congressional passage of a comprehensive bankruptcy reform bill. Although the President has said he would sign the bill, as of this writing, a conference committee had not yet met to resolve the significant differences between the House and Senate versions.
} 
Personal Bankruptcy Filings per 100,000 Persons

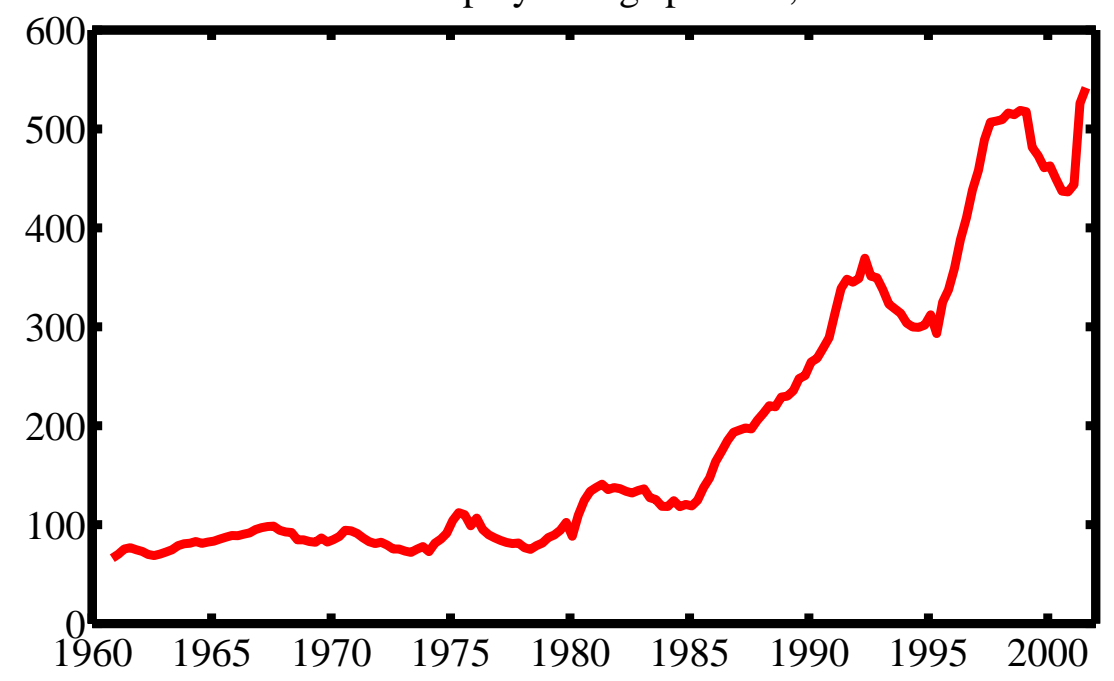

Total U.S. personal bankruptcy filings (Chapter 7 and Chapter 13) per 100,000 population, annual rate.

The literature on consumer bankruptcy (and, by extension, consumer debt) can be roughly divided into two camps. One the one hand, certain authors argue that households are not strategic in their use of bankruptcy law, while others argue that households value bankruptcy law the same way they would any other financial option, and act strategically given the actions of lenders and the prevailing law. One might characterize the former view as emphasizing the sociological aspects of consumption, debt and bankruptcy and the latter as emphasizing their economic aspects. ${ }^{4}$ Note that under either view, prevailing bankruptcy law can be critiqued as either too lax or too punitive.

\footnotetext{
${ }^{4}$ This characterization is a bit of an exaggeration, as recent economic research has moved away from the prevailing model of a unitary rational decision maker. See for example Harris and Laibson (2001).
} 
Sullivan, Warren and Westbrook $(1989,1997)$ advance a theory of consumption and bankruptcy in which a beleaguered middle class, overwhelmed by debt, uses bankruptcy as an insurance mechanism. In this view, most households are not strategic in their use of debt and bankruptcy; instead, they are seen as unfamiliar with the prevailing bankruptcy law in their state. Moreover, in this view, legal culture plays an all-important role in the outcome of a bankruptcy petition. Sullivan, Warren and Westbrook (1997), for example, compare outcomes across district courts in Pennsylvania and find wide disparities, despite having identical statutes. Further, Nelson (1999) finds that legal culture is one of the most important factors affecting whether households file under Chapter 7 or Chapter 13 of the bankruptcy code. These studies can be taken as evidence that changing bankruptcy laws would have little effect on household behavior so long as other, intangible cultural factors remained constant.

Gross (1997) also explicitly rejects the rational actor model, instead arguing that most households sincerely wish to meet their obligations and avoid harming their local communities. From this premise, she suggests, to choose one example, that bankruptcy laws ought to aim for equality of outcomes rather than equality of treatment. ${ }^{5}$ In the context of bankruptcy law, this could mean that all households are able to sustain roughly similar consumption levels after bankruptcy, no matter how different their debts before bankruptcy.

\footnotetext{
${ }^{5}$ Not all legal scholars take this approach; Baird and Morrison (2001) use a real options framework to discuss reform of corporate restructuring bankruptcy law; see also Denning, Ferris, and Lawless (2001) for an empirical analysis of corporate bankruptcy.
} 
However, other authors have found that households do indeed respond strategically to the prevailing bankruptcy law. For example, using data collected by the GAO on a random sample of bankruptcy petitions filed in 1980, Domowitz and Sartain (1999) study the decision to file for bankruptcy and, given that a household has decided to file for bankruptcy, the choice of Chapter. They find that households are more likely to file for bankruptcy after a job loss or a medical shock, thus buttressing the view that bankruptcy is an insurance mechanism. However, they also find that households respond to economic incentives built into the bankruptcy system, attempting to maximize the financial benefit to filing.

The Panel Survey of Income Dynamics (PSID) follows a large panel of individuals and households over time. In 1996, a special module of the PSID asked whether each member had ever filed for bankruptcy and, if so, in which year. Fay, Hurst, and White (1998) use information on income, assets, and debt in the PSID, matched with information on state bankruptcy laws, to construct measures of the potential economic benefit to declaring bankruptcy for each household. ${ }^{6}$ The authors find that households are more likely to file for bankruptcy as the financial benefit to doing so increases; and that households are less likely to file for bankruptcy as the stigma to doing so increases. The financial benefit to filing bankruptcy depends in part on state-level bankruptcy law; thus the authors demonstrate some relationship between state-level bankruptcy law and households' decisions

\footnotetext{
${ }^{6}$ The reported rate of bankruptcies in the PSID is well below that in the U.S. as a whole; this may be due to the PSID's sample or under-reporting due to shame or forgetfulness; however, the PSID rate may be below the national rate simply because the national bankruptcy statistics contain repeat filings of Chapter 13 petitions which a PSID participant might remember as a single event. (Chapter 13 filers often refile for technical reasons.)
} 
to file for bankruptcy.

Elul and Subramanian (1999) use the PSID to determine the extent to which state bankruptcy laws influence households' location decisions, particularly for households likely to declare bankruptcy. They find statistically significant evidence for forum shopping; that is, households more likely to declare bankruptcy are more likely to move to states with more generous bankruptcy laws.

Using the 1992 Survey of Consumer Finances, White (1998) finds that a substantial proportion - at least $15 \%$ - of households at any given point in time would benefit financially from declaring bankruptcy. However, by filing for Chapter 7 bankruptcy, households give up the right to file again for at least six years. White calculates the option value of bankruptcy - a cost to filing - and finds that it can be substantial. ${ }^{7}$

Finally, Olney (1999) studies the effect of bankruptcy law on households' consumption decisions during the Great Depression in the U.S. She compares consumption's sensitivity to income shocks before and after a major bankruptcy law reform in the early 1930s. She finds that households cut consumption more in response to income shocks under the less generous bankruptcy regime. Thus she concludes that punitive bankruptcy laws contributed to the consumption collapse of the early 1930s.

On balance, it appears that the evidence confirms that households do react strategically to their local bankruptcy laws. This paper is designed to fill three

\footnotetext{
${ }^{7}$ Household indebtedness rose through the mid-1990s and then leveled off, suggesting that White's calculations remain valid. See also Kennickell, Starr-McCluer, and Surrette (2000) and Durkin (2000).
} 
remaining lacunae in the literature:

1. To quantify the relationship between state bankruptcy laws (which are complex and varying along several different dimensions) and the aggregate bankruptcy rate in a given state, allowing us to predict roughly the change in a state's bankruptcy rate if it changes its exemption.

2. To determine the extent to which high bankruptcy exemptions encourage households to keep money in checking accounts earning low interest rather than using it to pay off their high-interest credit cards.

3. Authors who believe that households do not behave strategically and those who believe that they do agree that bankruptcy law provides an insurance mechanism. Our final goal is to test for the strength of these insurance effects.

\section{Model}

In this section we present a simple model of consumption and portfolio choice in the presence of Chapter 7 bankruptcy. We are interested in how bankruptcy rates, portfolio choice and consumption risk change as the Chapter 7 asset exemption changes. In general, we document that all of these phenomena have, in theory, a non-monotone relationship to the asset exemption. At very low exemptions, few households are willing to borrow, because they face a (small) risk of suffering a low income realization. Without the protection afforded by bankruptcy law, few 
households are willing to borrow, even at low interest rates. By contrast, at very high exemptions, the zero-profit lending industry will charge extreme interest rates and, again, few households will be willing to borrow.

However, over a broad range of intermediate bankruptcy asset exemptions, we show that:

1. Bankruptcy rates are increasing in asset exemptions.

2. Borrowing to save-holding a gross portfolio position different from the net portfolio position-is increasing in asset exemptions.

3. Consumption is less sensitive to income as asset exemptions increase.

We refer to this latter effect as an Olney effect, after Olney's (1999) paper demonstrating that tight bankruptcy laws played a part in the consumption collapse of the early 1930s.

The model we present here features a strong insurance role for unsecured debt; agents who are unlucky today will borrow to finance consumption in order to smooth consumption across periods. Sullivan (2002) uses the PSID to document that relatively wealthy households in fact do use unsecured debt to smooth consumption through transitory spells of unemployment.

\subsection{The Household's Problem}

In our model lenders and households will live for exactly two periods. Thus we are ignoring the option value of bankruptcy. In a companion paper to this one, 
Lehnert and Maki (2000), we explore the dynamics of borrowing and bankruptcy in a standard permanent income hypothesis model. ${ }^{8}$

Households value consumption streams $\left\{C_{0}, C_{1}\right\}$ as:

$$
U\left(C_{0}, C_{1}\right)=\frac{C_{0}^{\gamma}}{\gamma}+\beta \frac{C_{1}^{\gamma}}{\gamma}, 0<\beta \leq 1, \gamma<0
$$

Households are born with an initial endowment $Y_{0}$, which will vary across households in the economy, and then receive a second-period endowment of $Y_{1}$, drawn from the known distribution $G(\cdot)$. For simplicity, we assume that the initial endowments $Y_{0}$ are also distributed as $G$, and that the distribution of second period endowments is independent of the first period's endowment. We take the endowment shocks to be distributed lognormally, but with an additional risk of a very low endowment. Thus endowment $Y_{t}, t=0,1$ is:

$$
\begin{aligned}
Y_{t} & =\left\{\begin{aligned}
y & \text { with probability } \theta, \text { and: } \\
\bar{Y}_{t} e^{\varepsilon_{t}} & \text { with probability } 1-\theta
\end{aligned}\right. \\
\varepsilon_{t} & \sim \mathcal{N}\left(0, \sigma^{2}\right) .
\end{aligned}
$$

Here we take $y$, the endowment in the case that the household suffers the $\theta$-shock, to be quite small. We have in mind the small fraction of households that experience near-zero incomes (including transfer income) for more than a fleeting

\footnotetext{
${ }^{8}$ More generally, our model is a modified (and finite-horizon) version of the models of Zeldes (1989a,b), Deaton (1990), Hubbard, Skinner, and Zeldes (1994), Carroll(1992,1994), Carroll and Samwick (1998), and Engen (1993) to cite just a portion of the literature that uses numerical techniques to study consumption under uncertainty.
} 
moment. ${ }^{9}$

In the first period, $t=0$, households know their first-period income draw and choose their consumption and portfolio. Households will vary their decisions depending on their initial endowment draw. Note that each period's income distributions are centered about $\bar{Y}_{t}$; we will take $\bar{Y}_{1}>\bar{Y}_{0}$ to reflect growth in the household's potential labor income over time. Most households will want to borrow to smooth their increasing labor income profiles, minimizing consumption variation over time.

Households will have access to two securities in the first period of life: a low return liquid asset, $a$, which pays a gross return normalized to unity, and unsecured debt, $d$, which carries an endogenous gross interest rate of $r$. We will model households as choosing a face value for assets available and debt payable at the beginning of the second period of life, after $Y_{1}$ has been observed. Thus the household's period zero budget constraint is:

$$
C_{0}=Y_{0}-a_{1}+\frac{d_{1}}{r}
$$

In the second period of life, the household has liquid assets of $Y_{1}+a_{1}$ and liabilities of $d_{1}$. It has the option of filing for Chapter 7 bankruptcy or repaying its debt. If it files for bankruptcy, all liquid assets above the exogenous exemption level $X$ are seized to repay creditors, even as its unsecured debts are discharged. Thus the

\footnotetext{
${ }^{9}$ See Carroll (1992) for an estimate of the extent of this phenomenon using the PSID, or see figure 9(a) for evidence from the Consumer Expenditure Survey.
} 
household faces two budget constraints in the second (and final) period of life:

$$
\begin{aligned}
C_{1}^{\text {NoDef }} & =Y_{1}+a_{1}-d_{1}, \text { or: } \\
C_{1}^{\text {Default }} & =\min \left\{Y_{1}+a_{1}, X\right\} .
\end{aligned}
$$

Because we are using a two-period model, the household's sole motivation to avoid bankruptcy is losing liquid assets above the exemption. If we imagine that households lived for multiple periods, and valued the option to declare bankruptcy sometime in the future, as well as continued access to unsecured credit (which presumably would be cut off following a bankruptcy proceeding), households would be willing to trade the immediate pecuniary benefit of bankruptcy in order to keep their option. ${ }^{10}$ The option value of bankruptcy would thus depend on the household's future prospects, which, as we have stressed, is outside of the realm of this model. We can however proxy for this future value by specifying a non-pecuniary stigma penalty, denoted $\mathcal{F}$ (for "flogging"), assessed to households that declare

\footnotetext{
${ }^{10}$ Evidence on households' access to unsecured credit after bankruptcy is mixed. Although one hears anecdotes about households receiving large credit lines immediately after filing for bankruptcy, survey evidence by Visa, Inc., finds that few filers had access to unsecured credit a year after bankruptcy.
} 
bankruptcy. ${ }^{11}$ Thus the household's second period value function is:

$$
W_{1}\left(Y_{1}, a_{1}, d_{1}\right)=\max \left\{\frac{\left(C_{1}^{\text {NoDef }}\right)^{\gamma}}{\gamma}, \frac{\left(C_{1}^{\text {Default }}\right)^{\gamma}}{\gamma}-\mathcal{F}\right\} .
$$

For certain combinations of assets, debt and second-period income the household may be insolvent, that is, unable to repay its debts and achieve positive consumption, so that $C_{1}^{\text {NoDef }}<0$. In that case we take the utility of not declaring bankruptcy as negative infinity, so that insolvent households always declare bankruptcy.

One immediate consequence of our two-period formulation is that households will have a trigger income strategy for declaring bankruptcy. There will be a schedule of trigger incomes, $Y^{\star}\left(a_{1}, d_{1} ; X, \mathcal{F}\right)$, such that if the household enters the terminal period with assets $a_{1}$, debts $d_{1}$ in a society with a Chapter 7 exemption of $X$ and stigma of $\mathcal{F}$, the household will declare bankruptcy if and only if $Y_{1} \leq$ $Y^{\star}$

If the stigma of bankruptcy is zero, households will file for bankruptcy when it affords them the slightest increased consumption. In that case, consumption as

\footnotetext{
${ }^{11}$ Although we take this stigma to be a combination of the forgone option value of bankruptcy and the loss of easy access to convenient payment systems, there could also be a certain amount of shame associated with bankruptcy. Bankruptcy petitions list a debtor's assets, debts and ongoing liabilities; these petitions are public. The actor Burt Reynolds' petition, for example, listed several thousand dollars owed to the makers of his hairpieces. Further, even as late as the 18th century, defaulters were subject to flogging, transportation or confinement to a sponging house (which was as unpleasant as it sounds).
} 
a function of second period income is given by:

$$
C_{1}=\left\{\begin{array}{cl}
Y_{1}+a_{1} & Y_{1} \leq X-a_{1} \\
X & X-a_{1} \leq Y_{1} \leq X-a_{1}+d_{1} \\
Y_{1}+a_{1}-d_{1} & Y_{1} \geq X-a_{1}+d_{1} .
\end{array}\right.
$$

Notice that over a region of width $d_{1}$ consumption does not vary with income at all. On either side of this region, consumption moves one for one with income; for agents with bad income shocks, though, consumption is shifted up by an amount $d_{1}$. This is the sense in which bankruptcy law provides a (crude) form of insurance.

In the first period of life, then, the household solves the problem:

$$
W_{0}\left(Y_{0} ; r\right)=\max _{a_{1} \geq 0, d_{1} \leq \bar{d}}\left\{\frac{C_{0}^{\gamma}}{\gamma}+\beta E\left\{W_{1}\left(Y_{1}, a_{1}, d_{1}\right)\right\}\right\}
$$

Here consumption in period zero, $C_{0}$, is defined in equation (3) above, and the second-period value function $W_{1}$ is defined in equation (6) above. Expectations are taken with respect to hybrid income distribution $G$ defined in equation (2). The credit limit $\bar{d}$ is taken as exogenous; in practice we set it to the maximum possible value for $Y_{1}$, on the theory that no lender would make a loan certain to be defaulted upon. Denote the household's optimal choice of portfolio as $a^{\star}\left(Y_{0} ; r\right)$ and $d^{\star}\left(Y_{0} ; r\right) .{ }^{12}$

\footnotetext{
${ }^{12}$ Although the income distribution is lognormal and thus unbounded from above, our implementations use a finite support with a well-defined upper bound.
} 


\subsection{The Lender's Problem}

We model lenders as competitive entities that make zero profits in expectation. They charge a single rate $r$ on all unsecured loans; this rate does not vary with the borrower's initial endowment $Y_{0}$ or loan demand $d_{1}$. Lenders will also seek to maximize borrowers' expected utilities; in practice, this means that if lenders have multiple interest rates to choose from, they charge the lowest.

In developing the lender's zero-profit condition. it's useful to consider the expected profits associated with a household with a given income draw $Y_{0}$ in period zero:

(9) $\begin{aligned} \Pi\left(Y_{0}\right)=-\frac{d^{\star}\left(Y_{0} ; r\right)}{r}+ & d^{\star}\left(Y_{0} ; r\right) \times \operatorname{Pr}\left\{Y_{1} \geq Y^{\star}\left(a_{1}^{\star}, d_{1}^{\star} ; X, \mathcal{F}\right)\right\} \\ & +E\left\{Y_{1}+a_{1}^{\star}-C_{1}^{\text {Default }} \mid Y_{1}<Y^{\star}\left(a_{1}^{\star}, d_{1}^{\star} ; X, \mathcal{F}\right)\right\} .\end{aligned}$

We do not permit lenders to charge credit spreads $r$ that vary with the borrower's first-period income (although a conceptually simply extension, it generates computational difficulty). Thus the lender may or may not break even on a loan to a borrower of a particular type, $Y_{0}$; however, across all borrowers of all types, we require the lender to make non-negative profits. Thus the lender's zero-profit condition is:

$$
\int_{0}^{\infty} \Pi(s) d G(s) \geq 0
$$

Lenders choose an interest rate $r$ in full knowledge of the borrowers' problems 
(including the initial distribution of income in the economy); certain borrowers have a higher probability of declaring bankruptcy than others but, evening out over the whole population, the lender breaks even.

\subsection{Credit Limits}

Given our setup, one might suspect that households will pursue a strategy of borrowing as much as possible in the first period and choosing a portfolio in which $a_{1}=X$. Thus the household is guaranteed potentially unbounded consumption in the first period and positive (indeed, riskless) consumption in the second period. ${ }^{13}$ In this scenario, our exogenous credit limit $\bar{d}$ would determine the optimality of the maximal borrowing strategy. This in turn would make our theoretical model much less compelling, because we do not allow the lender to choose $\bar{d}$. We now show that because we assume that the risk aversion parameter satisfies $\gamma<0$, the maximal borrowing strategy stands little chance of being optimal. Thus our credit limit will not be binding in equilibrium.

Intuitively, the marginal utility of consumption drops so quickly that, even if consumption is unbounded, utility will still be finite. Pursuing a strategy of heavy borrowing followed by certain default may not be better than a strategy of equating expected marginal utilities across periods in the normal Euler-equation fashion. This results depends heavily on a functional form assumption for the utility function; with other utility functions in which marginal utility does not decline

\footnotetext{
${ }^{13}$ This is equivalent to a strategy of maxing out one's credit cards and using the proceeds to buy a house in Florida (where all housing equity is exempt from seizure by creditors) before filing for Chapter 7 bankruptcy.
} 
so sharply, the maximal-borrowing strategy may be more likely to be optimal.

Notice first from the definitions of $W_{1}$, equation (6), and consumption after default, equation (5) that $W_{1}$ satisfies:

$$
\lim _{d \rightarrow \infty} E\left\{W_{1}\left(Y_{1}, X, d\right)\right\}=\frac{X^{\gamma}}{\gamma}-\mathcal{F}
$$

This term is clearly finite. Meanwhile, examining the definition of utility in the first period of life, equation (8), we see that the maximal-borrowing strategy yields:

$$
\lim _{d \rightarrow \infty} \frac{(d-X)^{\gamma}}{\gamma}=0
$$

Thus the maximal-borrowing strategy gives an expected utility of:

$$
\frac{X^{\gamma}}{\gamma}-\mathcal{F}
$$

Again, this is clearly finite. There is no guarantee, moreover, that it will exceed the interior maximum for some $d_{1}<\infty$. Figure 1 contrasts the interior optimum versus the maximal-borrowing strategy. Notice that even as borrowing goes to infinity when assets equal the exemption, the interior solution is still optimal.

\subsection{Numerical Solution}

We solve our model numerically. Our particular parameter values are shown in the chart below. In our experiment we vary the bankruptcy exemption $X$ between 
0 and 2. For exemptions above about 1.45 , though, no solutions exist in which lenders make non-negative expected profits.

\begin{tabular}{|c|c|c|}
\hline \multicolumn{3}{|l|}{ Preference Parameters } \\
\hline Risk-aversion & $\gamma$ & -2.0 \\
\hline Discount factor ........ & $\beta$ & 0.9 \\
\hline Bankruptcy stigma............... & $\mathcal{F}$ & 0.1 \\
\hline \multicolumn{3}{|l|}{ Technology Parameters } \\
\hline First period mean income..... & $\bar{Y}_{0}$ & 1.0 \\
\hline Second period mean income ... & $\bar{Y}_{1}$ & 1.5 \\
\hline Normal income shock variance......... & $\sigma$ & 0.1 \\
\hline Probability of low shock ............ & $\theta$ & 0.015 \\
\hline Low income realization $\ldots \ldots \ldots \ldots \ldots$ & $y$ & $e^{-5}$ \\
\hline
\end{tabular}

NoTE. Chart shows the parameter values used in the numerical solution to the model.

We first present some figures establishing the nature of our model, and then we turn to presenting evidence of the various effects that we test in the empirical section. In figure 2 we show the probability distributions over income draws in the first and second periods. Recall that the distribution in the first period is fixed and known from the point of view all agents in the economy; further the second period probability distribution over income draws is independent of the first period's and hence the same for all agents in the economy. Notice that mean income grows; because $\gamma=-2$, this income growth provides a motive for households (even ones with relatively high first-period income draws) to borrow in the first period 
to smooth consumption. Notice also the distinct mass point at a low income level; this is the catastrophically low income identified by Carroll (1992) and others.

In figure 3 we show the lender's expected profit schedule as functions of interest rates $r$ for several different values of the exemption level $X$. Notice that when $X=0$, the lender makes nearly zero profits at all interest rates; few agents wish to borrow. At higher exemptions, by contrast, the lender cannot make positive profits at any interest rate. At an intermediate exemption level (marked) the lender has a choice of several interest rates that produce zero profits in expectation. In a competitive market, the lender chooses the utility-maximizing interest rate (the minimum interest rate).

Clearly, both borrower welfare and the interest rates charged by lenders will vary with the exemption. As we have seen, debt with bankruptcy is a crude form of insurance; thus we would not expect that zero exemptions to be Pareto optimal. In figure 4 we display the social welfare function as a function of the exemption. The global maximum is marked with a star; note that this optimal exemption is relatively high. In the same way, in figure 5 we plot the interest rate charged by the lender as a function of the exemption. The optimal exemption is again marked with a star. Notice that in both figures, at exemptions just above the optimal, the equilibrium quickly deteriorates. Interest rates jump and expected utilities fall. Some intuition for this can be derived from figure 3 , which shows that the lender's profit function is multi-peaked. As the peak associated with low interest rate falls below zero, the lender switches to a high interest rate strategy. These extreme reactions are the result of the two-period nature of the model; a model with richer 
dynamics would feature a less extreme deterioration in social welfare.

Finally, we are ready to establish the central facts of interest. The three panels in figure 6 demonstrate the relationship between bankruptcy law asset exemptions and (a) bankruptcy rates, (b) the percent of agents borrowing to save, and (c) the correlation of second period consumption and income (the Olney effect). All of these relationships are non-monotone in the exemption level; at relatively high levels of the exemption amount, no debt contract exists and the solution collapses to autarky, in which the household must use the low-return liquid asset as a buffer stock. At lower levels of the exemption level, in which solutions do exist, bankruptcy rates, the extent of borrowing to save and the Olney effect all exhibit a "U"-shaped relationship with the exemption level.

\section{Data}

Overview To test the implications of our model, we will use three slightly different datasets. Our first database comprises annual state-level variables from 1984-1999, including income, population, average house prices, unemployment and, most importantly, our measures of each state's Chapter 7 bankruptcy asset exemption. We shall refer to this database as our bankruptcy law database.

Our second two databases are nested subsets of the Consumer Expenditure Survey (known as the CE). The CE interviews a rotating panel of households five times with the interviews spaced three months apart. Responses to the first interview are not part of the public use micro dataset for privacy reasons, but 
responses in all subsequent interviews (second through fifth) are. Further, for all but about $20 \%$ of observations, we know the household's state of residence. We can thus match these households with the prevailing bankruptcy law that they face. For more detail on the $\mathrm{CE}$ and the particular questions that we used, see appendix A.2.

Our second database, which we refer to as the portfolio database, comprises those households in the CE with valid responses to the CE's questions about portfolios. At the fifth interview, participants are asked about their holdings of financial assets and about their unsecured debts outstanding. We are particularly interested in holdings of liquid assets, defined as transaction accounts plus savings accounts, which presumably pay a relatively low return in return for their liquidity. We are also interested in the quantity of unsecured debt outstanding, for which lenders presumably charge a spread over the low-risk, liquid return paid on liquid assets.

Our final database, the insurance database, comprises those households in the portfolio database for whom we have valid income and consumption measures at the second and fifth interviews. Thus the insurance database exploits the short panel nature of the CE. For more detail on how we constructed the CE databases, see appendix A.4.

Bankruptcy Law Coding bankruptcy laws is a necessarily complex procedure. For further details on these laws and on the construction of our bankruptcy law database, see appendix A.1. In a nutshell, though, we faced the problem of gen- 
erating a scalar value of each state's Chapter 7 bankruptcy asset exemption level for married homeowners, single homeowners, married renters and single renters in each year.

The most crucial distinction in the law is between homeowners and renters. Homeowners have access to each state's homestead exemption, the exemption applied to equity in a home used as a primary residence. Homestead exemptions vary considerably, from zero in Delaware and Maryland, to explicitly unlimited in Florida, Texas and three or four other states. ${ }^{14}$ Renters, by contrast, have access only to a state's personal exemptions, which are not only significantly lower, on average, than homestead exemptions, but are also often complex and assetspecific. Note that homeowners may claim both the local homestead exemption and the personal exemption.

States also differ in their treatment of married filers: Some allow doubling of exemptions, some take no notice of a filer's marital status and others make special provisions for married filers.

Exemption Quartiles Because we are probably measuring bankruptcy law with error, we create exemption quartiles to use as our primary regressors. Moreover, even if we measured bankruptcy law perfectly, there is still the issue of how to classify states with unlimited homestead exemptions. Here, they are simply assigned to the top quartile. The precise details of the construction of these quartiles, as well as descriptive statistics by quartile, are contained in appendix A.3.

\footnotetext{
${ }^{14}$ Minnesota capped its homestead exemption in 1993, and Iowa's homestead exemption can be as large as $\$ 1,000,000$.
} 
We created two classes of quartile: the U.S. quartiles treat all 51 states equally over the entire sample period. Thus in constructing the quartile ranks for married homeowners (for example), we first deflated the nominal exemptions set by law for married homeowners in all states and all years and then divided the resulting 816 state-year combinations into four groups of 204 state-years each.

By contrast, $C E$ quartiles are based on households in the CE. We matched each married homeowner (for example) to the real prevailing bankruptcy exemption available to it. We then produced quartiles from among this sample. Because the CE suppresses the state identifiers of all households from about eight states (for privacy reasons), it is possible that the $\mathrm{CE}$ is not a representative sample of the distribution of national bankruptcy law. In appendix A.3 we demonstrate that the distribution of states in the CE quartiles closely approximate the U.S. quartiles. We also show that the quartiles do not generally favor one part of our sample over another; that is, the nominal bankruptcy exemptions changed often enough to prevent variation over time from being driven entirely by the deflator.

\section{Results}

\subsection{Testing the Effect of Law on Bankruptcy Rates}

We begin by showing that our constructed quartile variables explain state-level Chapter 7 bankruptcy rates. A few other papers have examined the link between bankruptcy exemptions and bankruptcy rates, including Mulligan (2001) 
and Hynes (1998). ${ }^{15}$ Hynes (1998) (chapter 2) uses panel data from 1980-1998 on states to estimate linear probability and grouped probit models of bankruptcy rates with a variety of measures of the generosity of state-level bankruptcy laws. He finds, generally speaking, that being in the top quartile of states is associated with a higher filing rate; however, his results are of smaller magnitude than ours, and are sensitive to specification, whereas our results are both economically and statistically significant and robust to changes in specification. The main differences in our results appear to be in the effect of the personal (renter) exemptions, where measurement problems (as we discussed) are greatest. ${ }^{16}$ In addition, White (1987) and Nelson (2000) examine the effect of the 1978 Bankruptcy Reform Act on household bankruptcy filings. We find that a plausible bankruptcy reform measure (although, we emphasize, not the one currently before Congress) would lower Chapter 7 filings more than 18 percent.

Further, the result provides some assurance that we are actually measuring bankruptcy law fairly well, despite the inherent difficulties in coding the laws. For these empirical results, we cannot use the household-level datasets that we constructed, because they do not contain information on households' bankruptcy

\footnotetext{
${ }^{15}$ Mulligan (2001) uses a cross-section of states in 1993 and controls for socio-economic and other legal variables (such as wage garnishment) that do not change much over time, but that do have powerful effects on bankruptcy rates. Because we have constructed a panel of states, we can work, in essence, with first-differences by state and ignore such factors.

${ }^{16}$ It is worth noting that our results are also largely unchanged when we allow for dynamic effects, such as a time trend, serial correlation among the errors or a lagged dependent variable. Bankruptcy filing rates might be auto-regressive if bankruptcy had a contagion effect, in which one household's likelihood of filing increases if its neighbor files. A complete discussion of this subject is beyond the scope of this paper; however, it is the subject of ongoing research using census-tract level data and the cross-border estimator used by Pence (2001).
} 
decisions. Instead, we must use the purely state-level database that we constructed.

\section{Model and Tests}

We model an individual $i$ living in state $s$ and year $t$ as having a probability $\pi_{i}$ of declaring $\left(p_{i}=1\right)$ or not declaring $\left(p_{i}=0\right)$ Chapter 7 bankruptcy. We take $\pi_{i}$ to be proportional to the state's bankruptcy exemption quartile, unemployment rate, average real per-capita personal income growth, and house-price growth. ${ }^{17}$ Unemployment and per-capita income growth we take as measures of transitory income shocks and risk, while house price appreciation we take as a measure of permanent income growth (see Poterba 1991 for evidence that regional house prices are forward-looking). In addition, we include a full set of state and year fixed effects to control for unobserved state-level and annual variation. Sample means of the relevant state controls conditional on exemption status are shown in table 1.

We do not observe the individual's bankruptcy decision, $p_{i}$, only the aggregate result of all individuals' decisions in a particular state-year combination, $P_{s, t}$. Moreover, we do not know, in a given state-year, how bankruptcy filers split by housing tenure (i.e. owning vs. renting one's residence) and marital status. Thus one can envision two separate procedures: testing the effect of each definition of

\footnotetext{
${ }^{17}$ In addition, we have experimented with including other variables, including state Chapter 13 bankruptcy rates and state population growth rates among many, many other variables, and nonlinear transformations and lagged values of our explanatory variables; these had some explanatory power but did not affect the coefficients of interest.
} 
the U.S. quartiles separately or jointly.

One potential problem with any joint test of the effect of bankruptcy law provisions for different types of filers is that states' quartile ranks do not differ significantly by marital status. In other words, states that are generous towards single filers are likely to be generous to married filers as well. This makes identifying the effect of marriage provisions in the law difficult. Table 2 shows the distribution of states across married homeowner quartiles conditional on their single homeowner quartile rank and their single renter rank. As the table clearly shows, there is little variation between the single and married homeowner quartiles, but significant variation between the quartiles for married homeowners and single renters. Indeed, there appears at first glance to be no relationship between the two quartile rankings. ${ }^{18}$ Further, studies of bankruptcy filers show that a plurality of Chapter 7 filers are married homeowners, followed by single renters. In our joint study, then, we will use the quartile dummies for married homeowners and single renters.

\section{Empirical Specification and Results}

Given that our data are a series of individual decisions aggregated within states, we use a grouped version of a limited dependent estimator. We use a logistic model specification for ease of computation:

$$
\log \left(\frac{P_{s, t}}{N_{s, t}-P_{s, t}}\right)=b^{T o p} \delta_{s, t}^{T o p}+b^{2 n d} \delta_{s, t}^{2 n d}+b^{3 r d} \delta_{s, t}^{3 r d}+\mathbf{X}_{s, t} \cdot \mathbf{B}+\epsilon_{s, t} .
$$

\footnotetext{
${ }^{18}$ An easy way to check the relationship is to examine the principal diagonals of each matrix; in the first case, never less than $80 \%$ of observations share the same rank, in the second, never more than $50 \%$ do.
} 
Here $N_{s, t}$ is the total population in state $s$ and year $t$; the variables $\left\{\delta_{s, t}^{i}\right\}$ are indicator variables set to unity if state $s$ in year $t$ is in bankruptcy exemption quartile $i$; and $\mathbf{X}_{s, t}$ is a vector of other explanatory variables, which contains a full set of state and year dummy variables. The weights associated with each observation, $\omega_{s, t}$, are:

$$
\omega_{s, t}=N_{s, t} P_{s, t}\left(1-P_{s, t}\right)
$$

Note that $\omega_{s, t}$ is the inverse of the large-sample variance of $\epsilon_{s, t}$.

Coefficient estimates and robust standard errors for the four separate regressions are in table 3. Table 4 displays the same results for the joint regression, which includes quartile rank dummies for married homeowners and single renters.

Notice that bankruptcy laws do have a powerful effect on bankruptcy rates. Further, the largest coefficient is associated with the top quartile for married homeowners, the largest group of Chapter 7 filers. Finally, the coefficient estimates generally become smaller as one moves down exemption quartiles.

Comparing the results from the separate regressions and the joint regression, (table 3 versus 4 ) we see that the estimated coefficients do not substantially change from one specification to the other.

\section{Policy Experiment}

With the coefficient estimates from the joint study, table 4, we can determine the effect of the following policy experiment: Capping homestead exemptions so that 
all states currently in the top three quartiles are forced into the bottom quartile of homeowner exemptions, but leaving the personal exemptions untouched. Proposals of roughly this form have been floated; indeed, it is precisely the treatment of the homestead exemption that divides the Senate and House versions of the current bankruptcy law reform bill. We emphasize, however, that our policy experiment is at best stylized, and is mainly intended to demonstrate the relative importance of bankruptcy law in our empirical results.

With the logistic specification, the predicted number of bankruptcies in a state in the top exemption quartile (for married homeowners) is:

$$
\frac{\widehat{P}_{s, t}}{N_{s, t}}=\frac{\exp \left(b_{m h}^{\text {Top }}\right) \exp \left(A_{s, t}\right)}{1+\exp \left(b_{m h}^{\text {Top }}\right) \exp \left(A_{s, t}\right)},
$$

where $A_{s, t}$ is the net effect of all other variables and their estimated coefficients and $b_{m h}^{\text {Top }}$ is the coefficient on the top quartile indicator variable for married homeowners. Imagine forcing this state into the bottom quartile of bankruptcy exemptions for married homeowners only while leaving the state's relative rank among single renters untouched. The new predicted number of bankruptcies is (with $b_{m h}^{\text {Top }}$ set to zero):

$$
\frac{\widetilde{P}_{s, t}}{N_{s, t}}=\frac{\exp \left(A_{s, t}\right)}{1+\exp \left(A_{s, t}\right)}
$$


The relationship of $\widehat{P}$ to $\widetilde{P}$ is thus:

$$
\frac{\widetilde{P}_{s, t}}{\widehat{P}_{s, t}}=\exp \left[-\left(b_{m h}^{\text {Top }}\right)\right] \times \frac{1+\exp \left(b_{m h}^{\text {Top }}\right) \exp \left(A_{s, t}\right)}{1+\exp \left(A_{s, t}\right)}
$$

Because Chapter 7 bankruptcy rates are small (no state's bankruptcy rate ever exceeds one-half of one percent of its population), we can ignore the second term in this relation.

Similar arguments can be used for the other exemption quartiles, replacing $b_{m h}^{\text {Top }}$ with $b_{m h}^{2 n d}$ for the second rank of states and so on. Thus, in period $t$, the predicted number of bankruptcies following such a policy experiment would be:

$$
\begin{aligned}
\widetilde{P}_{t}=\sum_{s=1}^{s=51}\left\{\delta_{s, t}^{\text {Top }, m h} \exp \left(-b_{m h}^{\text {Top }}\right) P_{s, t}+\delta_{s, t}^{2 n d, m h}\right. & \exp \left(-b_{m h}^{2 n d}\right) P_{s, t} \\
& \left.+\delta_{s, t}^{3 r d, m h} \exp \left(-b_{m h}^{3 r d}\right) P_{s, t}\right\}
\end{aligned}
$$

We conduct the experiment in 1999 (the last year in our database). To conduct the experiment we need to know the aggregate number of Chapter 7 filings in 1999 by quartile, the estimated coefficients $b_{m h}^{T o p}, b_{m h}^{2 n d}, b_{m h}^{3 r d}$, and their exponential transformations. Given these facts we can compute the filings in each quartile under the experimental conditions:

\begin{tabular}{lrrrrr} 
& \multicolumn{3}{c}{ Married } & Homeowner & Exemption Quartile \\
& Top & 2nd & 3rd & Bottom \\
Chapter 7 filings $\ldots \ldots \ldots \ldots \ldots$ & 188,665 & 328,378 & 144,483 & 224,045 \\
Coefficient: $b_{m h}^{i} \ldots \ldots \ldots \ldots \ldots \ldots$ & 0.4540 & 0.2856 & 0.0803 & 0 \\
Effect: $\exp \left(-b_{\text {mh }}^{i}\right) \ldots \ldots \ldots \ldots$ & 0.6351 & 0.7516 & 0.9228 & 1 \\
Post-reform Chapter 7 filings ... & 119,821 & 246,808 & 133,329 & 224,045
\end{tabular}


In 1999, there were 885,571 total Chapter 7 bankruptcy filings. Under the proposed reform, we predict that there would instead have been only 724,003 filings, a decrease of 161,584 filings or more than 18 percent.

However, if instead of tightening their bankruptcy laws, states were instead to loosen them, so that all states moved to the top quartile of married homeowner exemptions, the effects would be relatively larger. In that case, we predict that there would have been approximately 250,000 more Chapter 7 bankruptcy filings, an increase of 29 percent. The effect of loosening exemptions is larger in part because of the pattern of bankruptcy filings across quartiles. The bottom quartile of states actually had the second-highest number of bankruptcy filings; these are the states that would be most affected by an increase in bankruptcy exemptions.

\subsection{Testing the Portfolio Choice Effects of Bankruptcy Law}

As shown in section 3, bankruptcy law encourages households to simultaneously hold low-return liquid assets and high-interest unsecured debt. In this section we present evidence that households living in states with higher bankruptcy exemptions are more likely to engage in this behavior.

One of our primary sources for bankruptcy law is the attorney's handbook by Williamson (published annually). ${ }^{19}$ These books explicitly recommend that bankruptcy lawyers advise their clients to convert as many of their assets as possible into exempt forms before filing for bankruptcy, a practice known as "negative estate planning." Thus, one can take our results here as evidence that negative estate

\footnotetext{
${ }^{19}$ See, for example, Williamson (1999).
} 
planning is more common in states with more generous bankruptcy laws.

\section{Definitions and Empirical Specification}

We first determine whether a given household is, in fact, "borrowing to save." As discussed in section A.2, the CE asks about the balance on checking and savings accounts, as well as for unsecured debt. For each household, we generate an indicator variable, BORRSAVE, set to unity if (1) both liquid assets and unsecured debt exceed a threshold level and, (2) liquid assets exceed $3 \%$ of gross income. We vary the threshold in thousand-dollar increments, from $\$ 2,000$ to $\$ 5,000$. Sample means from the dataset are presented in table 5.

Our general strategy is to divide households by housing tenure (owners and renters) and estimate probit regressions of the borrowing to save indicator variable on bankruptcy law variables and a full set of controls. In addition to bankruptcy law, we included indicator variables for whether the household head was married in the fifth interview, had a high school diploma, a college degree, or was a minority; we also included a full set of indicators for the nine different family types recorded by the $\mathrm{CE}$, indicators for the month of the fifth interview (to pick up seasonal effects) and indicators for the year of the fifth interview. We also included the level and the log of real total family income before taxes, the number of family members, the number of earners, the average age of the household head and spouse and age squared. For brevity, coefficient estimates for these control variables are not presented.

As bankruptcy law variables we used both the CE and the U.S. quartiles de- 
scribed in section A.3. In addition, some specifications include a full set of state fixed effects; identification in these specifications comes only from states that switch exemption quartiles over the time period.

\section{Results}

In table 6 we display selected results for regressions using the $\$ 2,000$ threshold for renters and the $\$ 5,000$ threshold for homeowners. (Complete results for all thresholds, as well as alternate specifications, are in appendix B below.) The table shows results from eight regressions: specifications estimated separately for homeowners and renters, both with and without a full set of state fixed effects and using either the U.S. or CE quartiles.

We find ample evidence that households in the top quartile of bankruptcy generosity are more likely to borrow to save than households in the bottom quartile of bankruptcy generosity. We estimate that homeowners living in states in the top quartile of bankruptcy exemptions are between $1 \%$ and $4.5 \%$ more likely to borrow to save than homeowners living in states in the bottom quartile (the excluded category). For the full sample, the incidence of borrowing to save among homeowners at the $\$ 5,000$ threshold is $7.5 \%$. Renters living in states in the top quartile of bankruptcy exemptions are at most $1.7 \%$ more likely to borrow to save than renters living in states in the bottom quartile; at the higher thresholds the effect vanishes, suggesting that renters, who are poorer on average than homeowners, are doing their borrowing to save at a lower level. The sample incidence of borrowing to save among renters at the $\$ 2,000$ threshold is about nine percent. 


\section{Robustness Tests}

We have already presented results from a wide variety of empirical specifications; in appendix B we present results from all thresholds. Inspecting tables B.1 through B.4, we see that for homeowners our results generally appear at all thresholds, while for renters they vanish at the higher thresholds. This is not surprising as the number of renters who borrow to save in our dataset also grows extremely small at high incomes.

However, so far we have not considered the possibility that bankruptcy law only affects one side of households' balance sheets. For example, households in high-exemption states might hold more debt than those in low-exemption states. One could imagine the story going in the other direction as well; households in generous states might have restricted access to unsecured credit and so hold larger precautionary balances. If the other side of the balance sheet is subject to enough measurement error, more people may appear to borrow to save in generous states.

We tackle this possibility directly by testing the effect of bankruptcy law on each side of the balance sheet, assets and liabilities. We repeat all of the exercises from our primary study above, except that now we replace the dependent variable BORRSAVE with strictly an asset or a debt version. That is, instead of testing whether both assets and debt exceed a threshold, we test only whether either does. To save space, we use only the CE quartiles.

The results using either purely a debt or an asset measure as a dependent variable are shown in table B.5 below. These regressions are precisely the same as the previous borrowing to save regressions, except that now the dependent vari- 
able is set to unity if either assets or debts exceed the indicated threshold. Notice that none of the bankruptcy law variables are significantly different from zero. As a statistical matter, bankruptcy law appears to have no effect on households' equilibrium debt choices. However, notice that for homeowners, the coefficients tend to be positive while for renters they tend to be negative. This accords with the findings of Gropp, Scholz, and White (1997), who documented that generous bankruptcy laws tend to restrict credit to the poor (mostly renters).

\subsection{Testing the Insurance Role of Bankruptcy Law}

The theory developed in section 3 also predicts the possibility of Olney effects, the increased sensitivity of consumption to income shocks in tight bankruptcy states. In states with low Chapter 7 exemptions, lenders are more willing to extend credit, which some households use to bring forward consumption. As a result, ex ante they are better off, but at the cost of servicing a large ex post debt burden. Almost mechanically, such a result requires households to cut consumption more in response to shocks. Note that our theory only raises the possibility that these effects would appear in equilibrium; it is by no means certain.

\section{Definitions and Measurement Issues}

We can use the CE's short-panel nature to test for the presence of these Olney effects; we know the household's reported gross total family income as it enters the survey and at its final interview. Moreover, we know whether the household becomes too sick to work or becomes unemployed over the course of the CE. In 
order to use the CE's short panel nature, we must delete many observations used in the analysis of portfolios in the previous section; full details on the construction of the restricted data set are in appendix A.4.

As we noted in section A.2, the CE also asks about the household's debt outstanding at the beginning of the second interview. Thus we can split households on the basis of their outstanding debt on the eve of entering the CE. One complication with this strategy is that we do not know whether a household has zero debt because it is thrifty or is credit constrained. Unlike the Survey of Consumer Finances, the CE does not ask whether a participant has been turned down for credit, or is discouraged from borrowing. Thus we will treat the approximately $37 \%$ of the sample that report having no debt at the second interview differently than those that report having some debt.

We define consumption as real expenditures on non-durables, excluding expenditures on educational services, health services, charitable contributions, and any housing-related expenditures, including rent, equivalent rent and imputed rents. The major components of this consumption measure are food (both at home and out), clothing, footwear, alcohol and tobacco. This is the same consumption measure used by Parker (1999) and Dynan and Maki (2001); but is slightly broader than the measure used by Souleles (1999).

Before we can analyze the effect of debt on consumption, we have to determine which households have an unusually high debt burden at the second interview. We choose two broad approaches, setting an absolute dollar threshold and setting a threshold debt to income ratio. For the absolute thresholds, we choose 
$\$ 3,000$ and $\$ 6,000$; as shown in figure 7 , these are about the 75 th and 87 th percentiles of real debt holdings. For the debt to income ratios we labeled those households with debt-to-income ratios above the median for all households with positive debt outstanding as high debt. We choose two measures of income: actual reported second interview income, and potential income at the second interview. We formed potential income by regressing log income on a variety of explanatory variables with a restricted data set that excluded those households who were too sick to work or involuntarily unemployed; we estimated the model's coefficients separately for homeowners and renters. The relationship between actual and potential income is displayed in figure C.1. The full specification and parameter estimates are reported in appendix C.

Thus we constructed four separate indicator variables of high debt. Table 7 displays sample means for a variety of variables in each realization of the debt indicator. One arresting observation is that households with zero debts have the fastest income and consumption growth; at the same time, they have the lowest level of income, homeownership rate and are least likely to be married. These zero-debt households, however, are more likely to be minorities and less likely to have high school or college degrees. Thus we conclude that zero-debt households are in general relatively poor and high-risk. However, we shall also argue that the group of zero-debt households conceals heterogeneity, with some of the households being relatively wealthy.

Note also that households with high debt in the sense of a high absolute level of debt are different from households with high debt in the sense of a high ratio 
of debt to income. These differences are robust to changes in the threshold level of debt, and to whether actual or potential income is used. Households with high levels of debt appear have higher permanent incomes than households with high ratios of debt to income. Under the level criterion, high debt households are more likely to own their homes, have college degrees and to be married; under the ratio criterion these differences are exactly reversed. In addition, while high debt households under the level criterion have much higher incomes than their low-debt counterparts, high debt households under the ratio criterion have only slightly higher incomes. This fact reassures us that the ratio criterion is not driven by households with extraordinarily low incomes.

We can address the nature of zero-debt households, and the differences between households satisfying our various high-debt criteria, by plotting the empirical distribution of income (figure 8) for each group. Three striking facts emerge from these figures. (1) The group of zero debt households does appear to contain a wide variety of household types. The income distribution of zero debt households is more or less flat among incomes from $\$ 18,000$ to $\$ 75,000$. (2) Using a level criterion produces two sets of households with dissimilar incomes; high-debt households clearly have higher incomes. (3) By contrast, using a ratio criterion produces two sets of households with similar incomes. In the same vein, the particular choice of threshold, or income (for the denominator), does not seem to affect the distribution of households.

Considering these facts, we use a ratio measure to classify households as high debt or low debt. To avoid misclassifying households with temporarily low in- 
come, we use the ratio of debt to potential income as our measure.

\section{Empirical Test}

We wish to test whether high debt households' consumption in tight bankruptcy states is more sensitive to changes in income than high debt households' consumption in generous bankruptcy states. As a preliminary step, we display the empirical distributions of income and consumption changes in figure 9. The income shocks have the unusual feature that they are either quite small (tightly centered around zero) or quite large, with income increasing or decreasing by more than a factor of five in about $2 \%$ of cases (marked with the grey dots in the figure). These large changes reflect households that experienced or recovered from a devastating income shock, e.g. unemployment or illness, or misreported their income at one interview. Notice that the distribution of consumption assumes a more conventional shape, not showing the extreme points that income shocks do.

As an initial trial of the hypothesis, we can simply calculate the average log difference in consumption for every combination of debt status and bankruptcy exemption quartile (table 9).

In our analysis we want to measure the treatment effect of tight bankruptcy law on high-debt households. Clearly, households' access to credit and desire to borrow will in turn depend on the local bankruptcy law. Thus the road to debt will be different in different states; however, the reaction of consumption to an income shock ought to allow us to measure the effect of bankruptcy law. Because consumption's reaction to income shocks may well depend on state-specific effects, 
we also include a full set of state-level indicators.

We thus estimate the parameters for the following regression equation for each of the three debt groups that we have defined (zero debt, low debt and high debt):

$$
\begin{aligned}
& \Delta \log \left(c_{i}\right)=a_{0}+\delta_{i}^{\text {Top }}\left[b^{\text {Top }}+\gamma^{\text {Top }} \Delta \log \left(y_{i}\right)\right] \\
& +\delta_{i}^{2 \text { nd }}\left[b^{2 \text { nd }}+\gamma^{2 \text { nd }} \Delta \log \left(y_{i}\right)\right]+\delta_{i}^{3 r d}\left[b^{3 r d}+\gamma^{3 r d} \Delta \log \left(y_{i}\right)\right] \\
& +\delta_{i}^{\text {Bottom }}\left[b^{\text {Bottom }}+\gamma^{\text {Bottom }} \Delta \log \left(y_{i}\right)\right]+\mathbf{X}_{i} \cdot \mathbf{B}+\epsilon_{i}
\end{aligned}
$$

We are most interested in how the consumption of a high debt household reacts to income shocks relative to the consumption reaction of a low debt household. Because we will be cutting the dataset into fairly fine partitions, we provide sample sizes for all of the relevant bins in table 10 .

The estimated parameters using our ratio to potential income criterion are shown in table 11 . We find, broadly speaking, that the consumption of homeowners is more sensitive to income in high exemption states. For renters, by contrast, we do find some evidence Olney effects, with moderate-debt renters cutting consumption more in tight bankruptcy states than in lax states. For high-debt renters this pattern breaks down, but still holds on average between the top two and bottom two quartiles.

First, consider only high debt homeowners: their log consumption growth responds at a rate of 0.0426 to their log income growth in generous bankruptcy states; at the same time, consumption growth responds only at a rate of 0.0037 in 
tight bankruptcy states, which is not statistically different from zero. Thus consumption growth is actually less sensitive to income growth in tight bankruptcy states than in loose bankruptcy states. The pattern is the same for low debt homeowners, so that the difference between high and low debt households' response to income growth does not vary across states by bankruptcy generosity.

For renters the results are more complex; perversely, low debt households feel the effects of income shocks more keenly in tight bankruptcy states. For high debt households, the average consumption response to income growth is lower in the top two quartiles than in the bottom two quartiles, but the high sensitivity in the top quartile is still evidence against an Olney effect. Relatively low debt renters thus appear to be the single group that exhibits a clear form of the Olney effect, although an argument can be made that high-debt renters also appear to suffer from a form of Olney effect.

\section{Conclusion}

In this paper we analyzed the relationships among bankruptcy law, bankruptcy rates, portfolio choice and consumption. We used state-level and household-level data to test the effect of bankruptcy law variations. In particular we tested three propositions of interest to policy makers: (1) whether loose bankruptcy laws lead to increased bankruptcy rates, (2) what effect bankruptcy laws have on household portfolios and (3) whether bankruptcy law provides an appreciable form of insurance to households. 
We find that generous bankruptcy laws indeed lead to increased state-level bankruptcy rates and that they also discourage households from using their lowreturn liquid assets to pay off their high interest unsecured debt bills. We find some evidence that for renters, generous bankruptcy laws do appear to protect household consumption from income shocks. For homeowners, though, if anything the opposite seems to hold true, with generous bankruptcy laws actually making consumption more sensitive to income.

Our results bear on the debate surrounding bankruptcy law in the U.S. In particular, they shed light on the differential effects of bankruptcy law on homeowners and renters. If states severely restricted their homestead exemptions, our results suggest that Chapter 7 filings would decrease by $18 \%$, the incidence of borrowing to save would fall dramatically, and homeowners' consumption would be less sensitive to income shocks. At the same time, if states liberalized their personal exemptions (the exemptions that affect renters directly), our evidence suggests that bankruptcy filings and borrowing to save would increase only slightly, while renters' consumption would be less sensitive to income shocks.

Further, our paper is one of the few that attempts to discern an effect of unsecured debt on consumption. Although much work obviously remains to be done in this area, our results can be taken as evidence that high levels of debt do not, by themselves, threaten households' consumption. 



\section{A Data Issues}

\section{A.1 State Bankruptcy Laws}

Bankruptcy laws are replete with archaic or quirky exemptions, and thus difficult to code. As an example, we were faced with coding state bankruptcy statutes that permitted filers to exempt $100 \%$ of the value of a family pet, two mules, and a buckboard. In this section we explain our coding procedure and present some summary statistics.

Chapter 7 asset exemptions fall into two categories: Homestead and non-homestead exemptions. Homestead exemptions are applied to the equity in a home used as a primary residence. These exemptions are especially generous in the farm states of the Midwest (and often contain explicitly higher limits for homesteads used as farms), while Atlantic coast states have no homestead exemptions. The statutes creating homestead exemptions are explicit about the dollar amount protected from creditors. However, Florida, Kansas, Oklahoma, South Dakota, and Texas have unlimited homestead exemptions, as did Minnesota until 1993. Potentially, a debtor could convert millions of dollars in otherwise non-exempt assets to cash and purchase a house with the proceeds, leaving nothing for creditors. (In certain high-profile bankruptcies, this has indeed happened.) We coded these states as having a homestead exemption level equal to the largest single homestead exemption (with an explicit limit) among all other states in that year. This maximum state was always Iowa, which, under certain circumstances, allows a homestead exemption of $\$ 1,000,000 .^{20}$

Non-homestead (or personal) exemptions are murkier. In addition to a proliferation of different classes of assets, state laws frequently allow households to exempt $100 \%$ of the value of a specific type of asset. For example, many states exempt $100 \%$ of the value of clothing for personal use. In principle, a debtor could shift assets into such categories to elude creditors, although in practice bankruptcy courts might view such massive shifts as abuse of the system. We coded these categories as being equal to the maximum allowed exemption (again, with an explicit limit) in that category among all states in each year, reasoning that this amount represented the largest acceptable amount that a bankruptcy court would permit.

Some (but not all) states allow debtors to use the federal bankruptcy exemptions. In those states, if the federal exemptions were more generous, we coded the states' exemptions as equal to the federal in that year. If the state's own exemptions were more generous, we ignored this possibility.

Finally, some states allow married debtors to double their exemptions if they file jointly, while other states make explicit provisions for married filers, usually additional exemptions. In each state, we calculated the effective exemptions for single and for married

\footnotetext{
${ }^{20}$ This is so large that in our empirical work, we classified Iowa as having an unlimited homestead exemption.
} 
households.

Thus the exemptions available to households under Chapter 7 of the bankruptcy code depend on the household's housing tenure (owner or renter) and marriage status. To reflect this, in each state and in each year, we produced four separate measures of the exemption level, one each for married homeowners, single homeowners, married renters and single renters. Note that homeowners have available to them all of the non-homestead exemptions, so these are included in their exemption measures.

\section{A.2 The Consumer Expenditure Survey}

The Consumer Expenditure Survey (CE) is a rotating panel of about 5,000 households, each of whom is interviewed five times, at three month intervals. Each calender month, about a third of the sample is interviewed. The responses to the first interview are not part of the public use microdata set (for privacy reasons), but all interviews thereafter are available.

During the interviews, CE participants are asked about monthly periodic expenditures (e.g. housing, apparel, transportation, health care, insurance, and entertainment). In addition, CE participants are provided with diaries and asked to record higher-frequency expenditures (e.g. food, beverages, personal care products and tobacco).

The $\mathrm{CE}$ also contains financial information about participants. At the fifth interview only, participants are asked about their holdings of a variety of financial assets: ${ }^{21}$ (1) savings accounts, (2) checking, brokerage and other transactions accounts, (3) U.S. savings bonds, and (4) stocks, bonds, mutual funds and "other such securities." We are particularly interested in the first two categories, which are the most liquid and lowest-return asset classes. ${ }^{22}$ The recorded levels for all asset classes are top-coded, with the top codes changing over time; before 1996 all series were top-coded at $\$ 100,000$ (in nominal terms). Because we form variables central to our analysis from the CE's financial data, we eliminate all top-coded observations. To keep our sample consistent over time, we drop all observations with nominal values of $\$ 100,000$ or greater in any year. (This had no discernible effects on our point estimates.)

At the fifth interview, participants are also asked retrospective questions about their asset holdings (for each asset class) as of the first of the month one year ago. In other words, the question seeks the asset balances on the morning of the household's first day in the CE sample. However, these questions are subject to the well-known problems of poor recall and underreporting of sensitive behaviors or events. For example, participants may be loath to admit to investment losses. ${ }^{23}$

\footnotetext{
${ }^{21}$ The question asks about holdings "as of the first of this month."

${ }^{22}$ Dynan and Maki (2001) use the CE's information on securities holdings to study how stockholders' wealth reacts to stock market fluctuations.

${ }^{23}$ Subjects are separately asked whether the balance has increased, decreased or stayed the same;
} 
Participants are asked about their debts at the second and fifth interviews; specifically, they are asked about the total amount owed to creditors as of the first day of the interview month. Thus, the first information about debts is available three months after the first information about assets (derived from the retrospective fifth interview questions). The $\mathrm{CE}$ classifies creditors into eight categories: (1) revolving credit cards (including store, gas and general-purpose cards); (2) store installment credit accounts; (3) banks and savings and loan companies; (4) credit unions; (5) finance companies; (6) insurance companies; (7) medical practitioners not covered by insurance; and (8) other credit sources. Loans secured by housing assets are covered elsewhere in the CE. These debts can therefore be thought of as largely unsecured. As with asset variables, before 1996, debts were topcoded at $\$ 100,000$; we also excluded any observation with top-coded debts or debts that would have been top-coded under the more restrictive pre-1996 level.

We do not include information on housing assets (beyond tenure status) in our analysis. Although the CE provides consistent information about whether a participant owns his or her primary residence, it lacks detailed information about house value and financing for much of the sample. Starting with the 1988 waves of the CE, the BLS included self-reported information on house price, length of ownership and purchase price for homeowners. And starting with the 1992 waves of the CE, the BLS included self-reported information on mortgage payments and principle outstanding. Even after 1992, though, this information is not available for all homeowners.

To be included in the sample, observations had to satisfy the following criteria: (1) have a valid state identifier, (2) be a complete income reporter, (3) have only one consumer unit living in the residence, (4) have a valid fifth interview, (5) have positive gross family income, (6) have a valid age variable, and (7) have asset and debt information that is not missing and not top-coded. For more detail on the selection of observations from the CE, see section A.4.

\section{A.3 Constructing Exemption Quartile Ranks}

The CE provides limited information on the household's geographic location, including the state of residence. Thus we can potentially match the household with the prevailing state bankruptcy law.

Because of the BLS's privacy requirements when constructing the CE, our ability to match is limited. In particular, the BLS structures the CE so that the combined geographic information (state, urban/rural status and city size) cannot be used by analysts to uniquely determine a geographic area of less than 100,000 persons. Thus the BLS suppresses the state code for all households living in AR, IA, ME, MS, NM, and SD. The BLS further suppresses the state codes of some households living in CA, FL, GA, IL, KS, MI, MO,

the responses to these questions may be more robust to these problems. 
MN, NY, NC, OK, OR, TN, VA, and WA. Finally, for a small number of observations, the BLS replaces the household's true state identifier with another state's in order to preserve information about urban/rural status or population size; the BLS included information to identify such records. We discard all observations whose state identifiers were unavailable or tampered with, about $21 \%$ of the total sample.

We divided households into four quartiles, based on the generosity of the prevailing bankruptcy law for households of that type (owner or renter, married or single), referred to as the CE quartiles. Any particular household's quartile rank is unaffected by the state's treatment of households of other types. For example, a married homeowner could be classified in the top quartile while next door a single renter could be classified in the bottom quartile.

We also classified states (in each year) into quartiles separately for each possible combination of tenure and marital status (referred to as the U.S. quartiles.) The U.S. quartiles are not population-weighted, and each state-year combination is weighted equally. For both the U.S. and CE quartiles, we refer to the top quartile as the one associated with the most generous bankruptcy laws (the highest asset exemptions) and the bottom quartile as the one associated with the least generous bankruptcy laws (the lowest asset exemptions). The CE and U.S. quartiles will differ because the CE (as we have seen) excludes eight states from its geographically identified sample and because the CE quartiles divide households evenly. The U.S. quartiles, by contrast, use all 51 states and are not population weighted. Table A.3.1 gives means of state-level characteristics conditional on U.S. bankruptcy exemption quartile. Characteristics such as unemployment rates, population, and per-capita income do not appear to vary systematically with bankruptcy exemption quartile; surprisingly, though, neither do bankruptcy filing rates. The analysis in section 5.1, though, demonstrates that there is a causal link from bankruptcy law to Chapter 7 filing rates.

For our study to be a fair test of the effect of prevailing bankruptcy laws, the CE quartiles should do a good job of approximating the U.S. quartiles. We compare these quartiles in two ways; (1) by comparing their quartile rank cutoffs and (2) by distributing households from the CE survey into their appropriate U.S. quartile. First, figure A.3.1 displays the empirical cumulative distribution functions of exemptions (by tenure and marital status) for both the U.S. and the CE quartiles; table A.3.2 lists the associated dollar values. Second, table A.3.3 shows how CE households would be distributed across U.S. quartiles, conditional on their CE quartiles.

Examining figure A.3.1 and table A.3.2, we see that the differences in quartile cutoffs are small (less than $5 \%$ of the U.S. exemption level); and that the CE quartile cutoffs (marked in each panel on the figure) also do a good job of sorting the U.S. exemptions.

Examining table A.3.3 we see that the bulk of CE households are located along the principal diagonals; in other words, they would have the same quartile rank whether the U.S. or CE quartiles were used. 
We construct our quartiles treating each year-state (for the U.S.) or month-state (for the CE) combination as a separate observation. However, we are also deflating the exemptions faced by households, while the nominal exemptions (set by law) are changing relatively infrequently. Thus it could be that we are classing all states at the beginning of our sample (for example) as the most generous and all states at the end of our sample as the least generous. In table A.3.4 we display the distribution of married homeowner households from the $\mathrm{CE}$ across quartiles and years (the distributions for other tenure-marital status combinations are quite similar). Table A.3.5 displays the distribution of U.S. states in our sample across years and quartiles (using the exemptions for married homeowners). 
FIGURE A.3.1: Empirical cumulative distributions of CE and U.S. quartiles

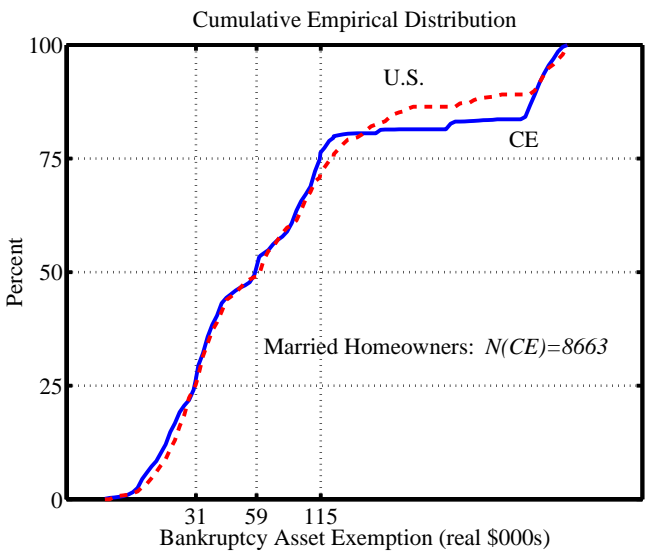

(a) Married homeowners

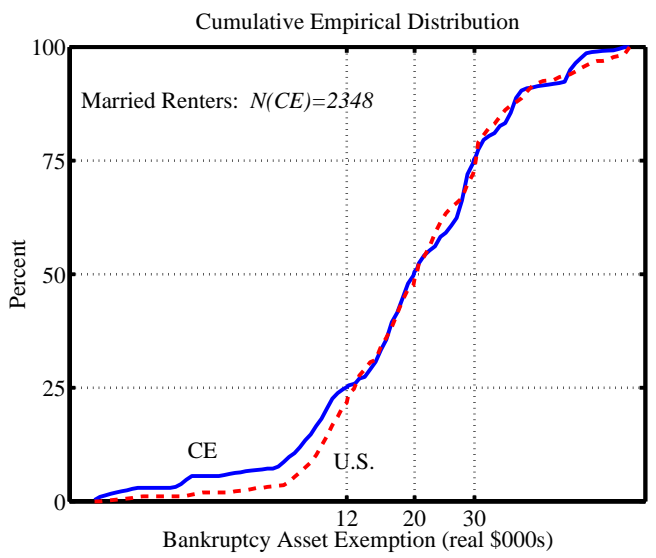

(c) Married renters

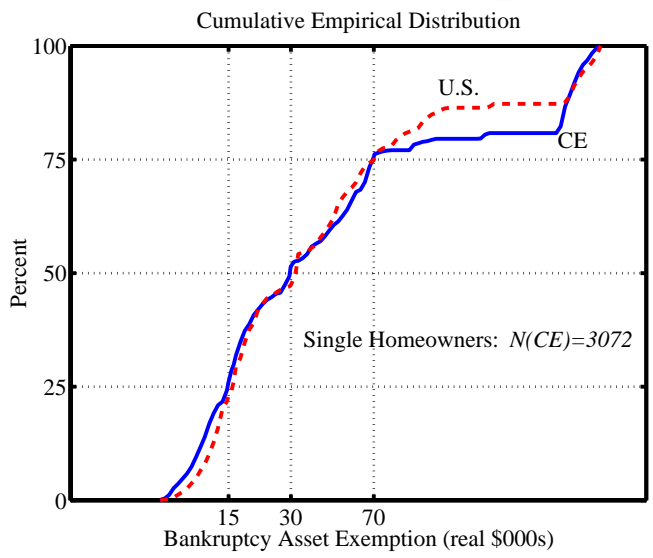

(b) Single homeowners

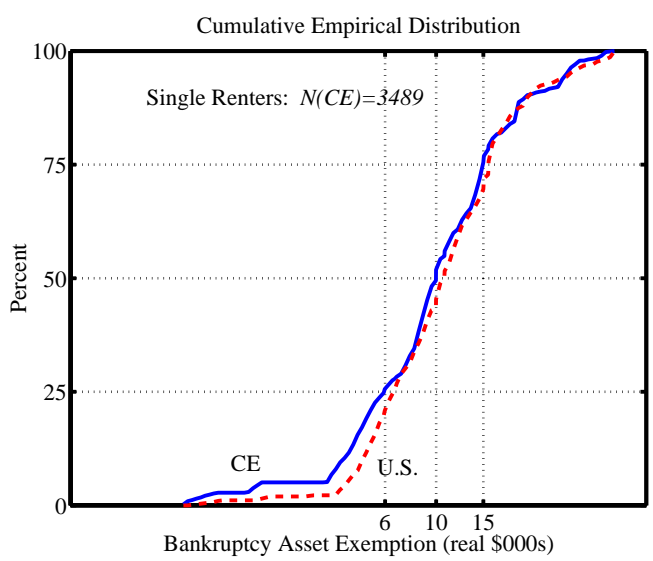

(d) Single renters

NoTE. Figure gives the empirical cumulative distributions of bankruptcy asset exemption laws for households in the $\mathrm{CE}$ and for states. CE quartile breaks are marked. 
TABLE A.3.1: Mean for U.S. States, 1984-1999

\begin{tabular}{|c|c|c|c|c|}
\hline & Bank & $\begin{array}{l}\text { tcy Exe } \\
\text { Married }\end{array}$ & $\begin{array}{l}\text { ion Qua } \\
\text { meown }\end{array}$ & (U.S.) \\
\hline & Bot. & $3 \mathrm{rd}$ & 2nd & Top \\
\hline Variable & & & & \\
\hline Chapter 7 Filing Rate ${ }^{a}$ & 0.22 & 0.18 & 0.22 & 0.23 \\
\hline & $(0.11)$ & $(0.11)$ & $(0.11)$ & $(0.12)$ \\
\hline Chapter 13 Filing Rate ${ }^{a}$. & 0.12 & 0.08 & 0.06 & 0.06 \\
\hline & $(0.13)$ & $(0.09)$ & $(0.05)$ & $(0.06)$ \\
\hline Population (millions) & 4.56 & 5.51 & 5.35 & 4.48 \\
\hline & $(3.27)$ & $(4.92)$ & $(7.65)$ & $(5.10)$ \\
\hline Per-capita income ${ }^{b}$. & 23.58 & 24.53 & 25.18 & 24.58 \\
\hline & $(3.94)$ & $(4.40)$ & $(4.91)$ & $(4.73)$ \\
\hline Unemployment Rate $^{a}$ & 5.64 & 6.13 & 6.14 & 5.33 \\
\hline & $(1.95)$ & $(1.75)$ & $(1.98)$ & $(1.56)$ \\
\hline
\end{tabular}

NotE. Table gives means of selected state-level variables from a dataset of all 51 states over the years 1984-1999; standard deviations are in parentheses.

\footnotetext{
${ }^{a}$ Percent.

${ }^{b}$ Thousands of real 1996 dollars.
} 
TABLE A.3.2: Quartile Rank Cutoffs

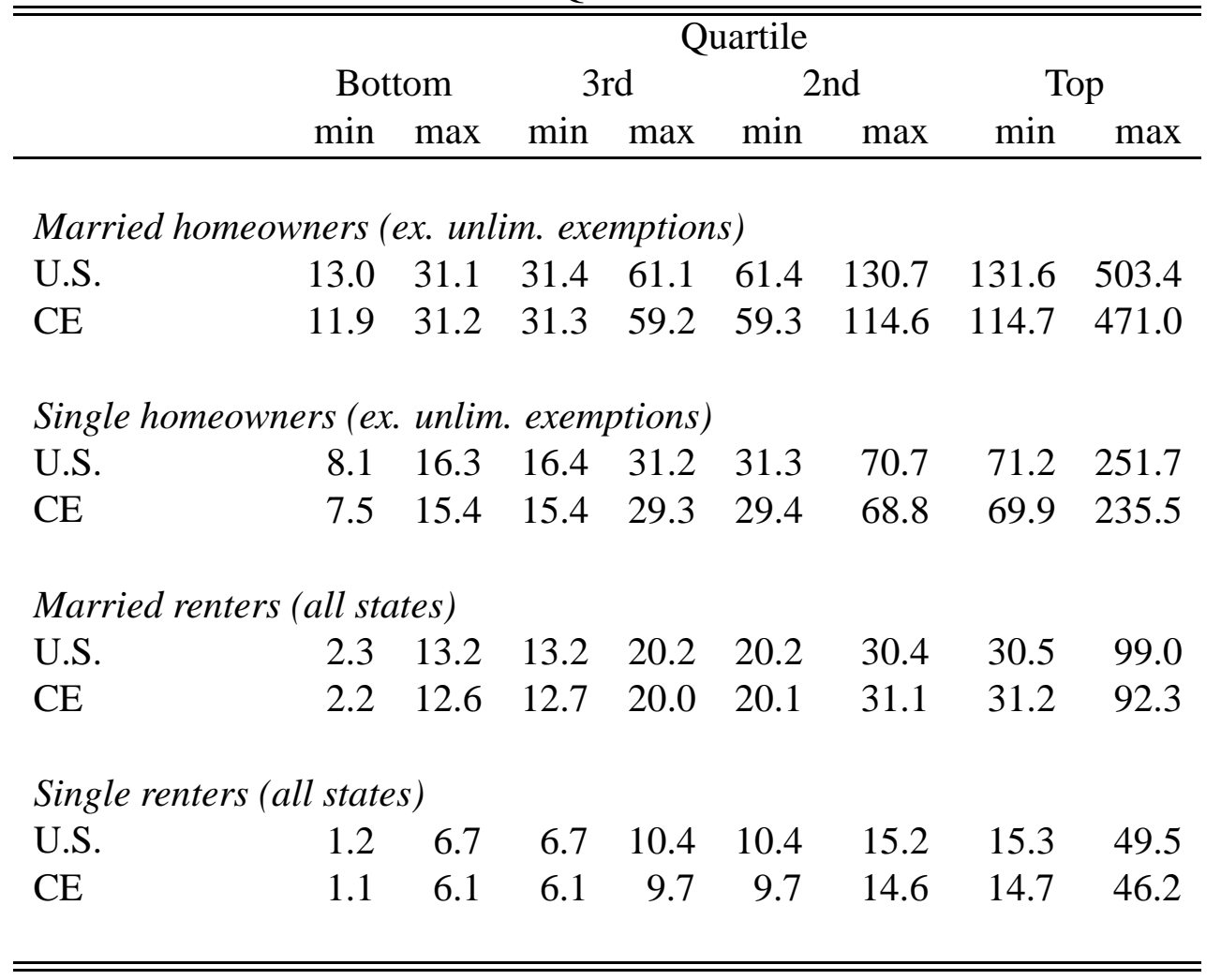

NOTE. Table gives the range of real bankruptcy exemptions in each quartile (for the indicated debtor type) in two different data sets. The first comprises all 51 U.S. states weighted equally, the second comprises the CE sample. Exemptions are in thousands of real 1996 dollars, deflated by the non-durables consumption deflator. 
TABLE A.3.3: Distribution of households across CE and U.S. quartiles

\begin{tabular}{|c|c|c|c|c|c|c|c|c|}
\hline \multirow[b]{5}{*}{ CE } & \multicolumn{7}{|c|}{$\overline{\text { Exemption Quartiles }}$} & \\
\hline & \multicolumn{4}{|c|}{ Married } & \multicolumn{4}{|c|}{ Single } \\
\hline & \multicolumn{2}{|c|}{ Homeowners } & & & & & & \\
\hline & \multicolumn{4}{|c|}{ U.S. } & \multicolumn{4}{|c|}{ U.S. } \\
\hline & Bot. & $3 \mathrm{rd}$ & 2nd & Top & Bot. & $3 \mathrm{rd}$ & 2nd & Top \\
\hline Bot. & 3,520 & 565 & 0 & 0 & 1,577 & 126 & 0 & 0 \\
\hline $3 r d$ & 0 & 3,737 & 377 & 0 & 12 & 1,653 & 63 & 0 \\
\hline 2nd & 0 & 0 & 4,053 & 0 & 0 & 6 & 1,363 & 309 \\
\hline \multirow[t]{3}{*}{ Top } & 0 & 0 & 350 & 3,706 & 0 & 0 & 0 & 1,700 \\
\hline & \multicolumn{8}{|c|}{ Renters } \\
\hline & \multicolumn{4}{|c|}{ U.S. } & \multicolumn{4}{|c|}{ U.S. } \\
\hline $\mathrm{CE}$ & Bot. & $3 \mathrm{rd}$ & 2nd & Top & Bot. & 2nd & 2nd & Top \\
\hline Bot. & 1,405 & 25 & 0 & 0 & 2,395 & 0 & 0 & 0 \\
\hline $3 \mathrm{rd}$ & 0 & 1,263 & 168 & 0 & 77 & 1,168 & 25 & 0 \\
\hline 2nd & 0 & 0 & 995 & 458 & 0 & 76 & 1,896 & 423 \\
\hline Top & 0 & 0 & 0 & 1,395 & 0 & 0 & 0 & 2,368 \\
\hline
\end{tabular}

NoTE. Table compares the CE and U.S. bankruptcy exemption quartiles by showing the distribution of CE households among U.S. quartile ranks. The CE quartiles are formed from the states in the CE; the U.S. quartiles use all 51 states. See text for further information. 
TABLE A.3.4: Distribution of Married Homeowners in CE

\begin{tabular}{rrrrrr}
\hline \hline & \multicolumn{4}{c}{ Exemption Quartiles } & \\
\cline { 2 - 5 } Year & Bot. & 3rd & 2nd & Top & Total \\
1984 & 30 & 127 & 76 & 43 & 276 \\
1985 & 138 & 438 & 357 & 180 & 1,113 \\
1986 & 223 & 434 & 311 & 255 & 1,223 \\
1987 & 304 & 383 & 316 & 312 & 1,315 \\
1988 & 274 & 319 & 243 & 260 & 1,096 \\
1989 & 290 & 320 & 254 & 262 & 1,126 \\
1990 & 307 & 343 & 190 & 326 & 1,166 \\
1991 & 282 & 318 & 262 & 287 & 1,149 \\
1992 & 379 & 236 & 202 & 274 & 1,091 \\
1993 & 424 & 143 & 246 & 313 & 1,126 \\
1994 & 257 & 169 & 362 & 312 & 1,100 \\
1995 & 257 & 280 & 214 & 250 & 1,001 \\
1996 & 272 & 228 & 170 & 356 & 1,026 \\
1997 & 301 & 215 & 288 & 287 & 1,091 \\
1998 & 276 & 118 & 427 & 260 & 1,081 \\
1999 & 71 & 43 & 135 & 79 & 328 \\
& & & & & \\
Total & 4,085 & 4,114 & 4,053 & 4,056 & 16,308 \\
\hline \hline
\end{tabular}

NOTE. Table gives the distribution of observations (for married homeowners) from the $\mathrm{CE}$ across years and quartile exemption ranks. Note that there is no particular bias towards one quartile or another over time. 
TABLE A.3.5: Distribution of U.S. States

\begin{tabular}{rrrrrr}
\hline \hline & \multicolumn{4}{c}{ Exemption Quartiles } & \\
\cline { 2 - 4 } Year & Bot. & 3rd & 2nd & Top & Total \\
1984 & 10 & 19 & 12 & 10 & 51 \\
1985 & 11 & 17 & 13 & 10 & 51 \\
1986 & 11 & 17 & 11 & 12 & 51 \\
1987 & 11 & 18 & 10 & 12 & 51 \\
1988 & 13 & 15 & 10 & 13 & 51 \\
1989 & 14 & 15 & 11 & 11 & 51 \\
1990 & 15 & 14 & 10 & 12 & 51 \\
1991 & 16 & 12 & 10 & 13 & 51 \\
1992 & 15 & 13 & 10 & 13 & 51 \\
1993 & 13 & 12 & 13 & 13 & 51 \\
1994 & 13 & 6 & 20 & 12 & 51 \\
1995 & 13 & 7 & 18 & 13 & 51 \\
1996 & 13 & 8 & 17 & 13 & 51 \\
1997 & 14 & 12 & 10 & 15 & 51 \\
1998 & 12 & 8 & 15 & 16 & 51 \\
1999 & 10 & 11 & 14 & 16 & 51 \\
\hline \hline
\end{tabular}

Note. Table gives the distribution of U.S. states across exemption quartiles (ranked by the exemptions for married homeowners) and over time. 


\section{A.4 Constructing the CE Microdata Sample}

Our initial sample gives us over 100,000 observations to begin with. However, we require that observations satisfy several criteria in order to be included in the final data sets. We have two sets of criteria: a base set and an additional series of extra restrictions. The base set of criteria comprise the bare minimum required for an observation to be included in our borrowing to save analysis in section 5.2 above. That is, these restrictions are merely enough to guarantee that we can form the dependent and control variables. In addition, we impose an extra set of restrictions to implement the consumption analysis in section 5.3 above. Thus to be included in the borrowing to save analysis, records had to have:

1. A valid state identifier.

2. Exactly one consumer unit (family) in the residence.

3. A valid fifth interview.

4. A non-missing value for household head's age.

5. Positive and non-missing income at the fifth interview.

6. Non-missing values for checking and savings accounts.

7. Non-topcoded checking, savings account and debt values.

In addition, to be included in the consumption risk analysis, in section 5.3 above, observations had to satisfy a further set of criteria. In particular, records had to have:

1. A valid second interview.

2. A log income difference between $1 / 3$ and 3; as well as positive income at both the second and the fifth interview.

3. Non-topcoded income in both the second and fifth interviews.

4. Age between 21 and 70 .

5. Complete debt information at the second interview.

6. Second interview non-durable consumption could not be below $\$ 1,000$ (in real 1996 dollars) or greater than $\$ 20,000$; in addition, second interview consumption had to exist.

7. Fifth interview consumption had to meet the same criteria.

From examining table A.4.1 below, we see that the most common reasons for eliminating a record from our datasets are missing interviews, a missing state identifier or missing asset, debt or income information. We did eliminate some records because their responses made us suspect misreporting; this is absolutely standard in the CE literature, see for example Parker (1999) or Dynan and Maki (2001). 
TABLE A.4.1: Construction of Dataset from the CE

\begin{tabular}{lrrrr}
\hline & Net Loss & \multicolumn{3}{c}{ Remaining } \\
Condition & & Owners & Renters & Total \\
& & 51,538 & 63,855 & 115,393 \\
Initial sample $^{a}$ & & & & \\
& & & & \\
Initial set of restrictions & & & & \\
& 25,758 & 39,937 & 50,573 & 90,510 \\
Invalid state & 1,165 & 38,787 & 50,558 & 89,345 \\
Duplicate record & 6,904 & 38,411 & 44,030 & 82,441 \\
Multiple CU & 22,872 & 38,411 & 21,158 & 59,569 \\
No 5th interview & 237 & 38,260 & 21,072 & 59,332 \\
Missing age & 8,826 & 32,392 & 18,114 & 50,506 \\
Bad 5th interview income & 10,566 & 24,517 & 15,423 & 39,940 \\
Bad 5th interview assets & 1,547 & 23,141 & 15,252 & 38,393 \\
Top coded assets & 39 & 23,117 & 15,237 & 38,354 \\
Top coded debts & & & & \\
& & & & \\
Additional set of restrictions & & & & \\
& 10,322 & 18,878 & 9,154 & 28,032 \\
No 2nd interview & 191 & 18,774 & 9,067 & 27,841 \\
Consumption violation $^{b}$ & 1,741 & 17,665 & 8,435 & 26,100 \\
Income violation $^{c}$ & 2,755 & 15,099 & 8,246 & 23,345 \\
Income topcoded $_{\text {Age }>\text { 70 or }<21^{d}}$ & 2,994 & 13,084 & 7,267 & 20,351 \\
Bad 2nd interview checking $_{\text {Bad 2nd interview saving }}^{2,152}$ & 11,677 & 6,522 & 18,199 \\
Bad 2nd interview cons. $^{e}$ & 2,403 & 10,019 & 5,777 & 15,796 \\
Bad 5th interview cons. $^{e}$ & 78 & 10,002 & 5,716 & 15,718 \\
& 53 & 9,973 & 5,692 & 15,665 \\
\hline
\end{tabular}

${ }^{a}$ Everyone who is not reported as a homeowner, including those with missing or incomplete tenure records and those neither owning nor renting their residences, are here classed as "renters."

${ }^{b}$ Log consumption difference exceeded 3 or was less than $1 / 3$.

${ }^{c}$ Second or fifth interview income negative, zero or missing.

${ }^{d}$ Age defined as the average of household head and spouse (if present).

${ }^{e}$ Consumption less than $\$ 1,000$ or greater than $\$ 20,000$ or missing. 


\section{B Further Portfolio Results}

We use four different thresholds for the borrowing to save variable; we display the estimated coefficients and cluster-adjusted standard errors for each threshold level in table B.1 ( $\$ 2,000$ threshold), table B.2 (\$3,000 threshold), table B.3 (\$4,000 threshold) and table B.4 ( $\$ 5,000$ threshold). Each table shows results from eight regressions: specifications estimated separately for homeowners and renters, both with and without a full set of state fixed effects and using either the U.S. or the CE quartiles. In some states, no household ever borrows to save; we dropped all observations from such states. 
TABLE B.1: Results of Borrowing to Save Model: \$2,000 Threshold

\begin{tabular}{|c|c|c|c|c|c|c|c|c|}
\hline \multirow[b]{4}{*}{ Top } & \multicolumn{8}{|c|}{ Probability Derivatives $\partial F / \partial x$} \\
\hline & \multicolumn{4}{|c|}{$\begin{array}{c}\text { Homeowners Only } \\
\text { Quartile }\end{array}$} & \multicolumn{4}{|c|}{$\begin{array}{l}\text { Renters Only } \\
\text { Quartile }\end{array}$} \\
\hline & \multicolumn{2}{|c|}{$\mathrm{CE}$} & \multicolumn{2}{|c|}{ U.S. } & \multicolumn{2}{|c|}{$\mathrm{CE}$} & \multicolumn{2}{|c|}{ U.S. } \\
\hline & $\begin{array}{c}0.0273 \\
(0.0124)\end{array}$ & $\begin{array}{c}0.0128 \\
(0.0233)\end{array}$ & $\begin{array}{c}0.0264 \\
(0.0130)\end{array}$ & $\begin{array}{c}0.0075 \\
(0.0244)\end{array}$ & $\begin{array}{c}0.0054 \\
(0.0046)\end{array}$ & $\begin{array}{c}0.0020 \\
(0.0137)\end{array}$ & $\begin{array}{c}0.0078 \\
(0.0041)\end{array}$ & $\begin{array}{c}0.0173 \\
(0.0147)\end{array}$ \\
\hline 2nd & $\begin{array}{c}0.0373 \\
(0.0107)\end{array}$ & $\begin{array}{c}0.0108 \\
(0.0208)\end{array}$ & $\begin{array}{c}0.0344 \\
(0.0112)\end{array}$ & $\begin{array}{c}0.0112 \\
(0.0212)\end{array}$ & $\begin{array}{c}0.0000 \\
(0.0045)\end{array}$ & $\begin{array}{c}0.0051 \\
(0.0118)\end{array}$ & $\begin{array}{r}-0.0049 \\
(0.0049)\end{array}$ & $\begin{array}{c}0.0084 \\
(0.0128)\end{array}$ \\
\hline $3 r d$ & $\begin{array}{c}0.0106 \\
(0.0111)\end{array}$ & $\begin{array}{c}-0.0029 \\
(0.0133)\end{array}$ & $\begin{array}{c}0.0030 \\
(0.0122)\end{array}$ & $\begin{array}{c}-0.0184 \\
(0.0151)\end{array}$ & $\begin{array}{c}-0.0032 \\
(0.0044)\end{array}$ & $\begin{array}{c}-0.0032 \\
(0.0097)\end{array}$ & $\begin{array}{c}-0.0004 \\
(0.0046)\end{array}$ & $\begin{array}{l}0.0045 \\
(0.0110)\end{array}$ \\
\hline $\mathcal{X}^{2}($ State $)$ & & $\begin{array}{l}112.43 \\
(0.0000)\end{array}$ & & $\begin{array}{l}115.42 \\
(0.0000)\end{array}$ & & $\begin{array}{c}52.68 \\
(0.0864)\end{array}$ & & $\begin{array}{c}54.89 \\
(0.0374)\end{array}$ \\
\hline States & 43 & 43 & 43 & 43 & 43 & 41 & 43 & 41 \\
\hline Successes & 4,788 & 4,788 & 4,788 & 4,788 & 1,361 & 1,361 & 1,361 & 1,361 \\
\hline Observations & 23,117 & 23,117 & 23,117 & 23,117 & 15,237 & 15,231 & 15,237 & 15,231 \\
\hline
\end{tabular}

NOTE. Table gives probability derivatives from a probit regression of BORRSAVE(with a cutoff of $\$ 3,000$ ) against explanatory variables, including bankruptcy exemption quartiles. CE quartiles are formed from the CE sample while U.S. quartiles are formed from the U.S. states over the sample period (see text for details). Some state dummy variables predict failure perfectly; all such states are dropped for regressions using state fixed effects. For regressions without state fixed effects, standard errors are corrected for clustering; robust, cluster-adjusted, standard errors are in parentheses. 
TABLE B.2: Results of Borrowing to Save Model: \$3,000 Threshold

Probability Derivatives $\partial F / \partial x$

\begin{tabular}{|c|c|c|c|c|c|c|c|c|}
\hline & & $\begin{array}{r}\text { Homeow } \\
\text { Qua }\end{array}$ & $\begin{array}{l}\text { zers Only } \\
\text { rtile }\end{array}$ & & & $\begin{array}{r}\text { Rente } \\
\mathrm{Qu}\end{array}$ & $\begin{array}{l}\text { s Only } \\
\text { rtile }\end{array}$ & \\
\hline & & $\mathrm{E}$ & & & $\mathrm{C}$ & & $\mathrm{U}$. & \\
\hline Top & $\begin{array}{c}0.0167 \\
(0.0117)\end{array}$ & $\begin{array}{c}0.0205 \\
(0.0201)\end{array}$ & $\begin{array}{c}0.0170 \\
(0.0122)\end{array}$ & $\begin{array}{c}0.0229 \\
(0.0210)\end{array}$ & $\begin{array}{c}0.0067 \\
(0.0042)\end{array}$ & $\begin{array}{c}0.0079 \\
(0.0103)\end{array}$ & $\begin{array}{c}0.0074 \\
(0.0040)\end{array}$ & $\begin{array}{c}0.0176 \\
(0.0112)\end{array}$ \\
\hline 2nd & $\begin{array}{c}0.0261 \\
(0.0087)\end{array}$ & $\begin{array}{c}0.0176 \\
(0.0179)\end{array}$ & $\begin{array}{c}0.0251 \\
(0.0095)\end{array}$ & $\begin{array}{c}0.0268 \\
(0.0182)\end{array}$ & $\begin{array}{r}-0.0002 \\
(0.0035)\end{array}$ & $\begin{array}{c}0.0093 \\
(0.0089)\end{array}$ & $\begin{array}{r}-0.0035 \\
(0.0036)\end{array}$ & $\begin{array}{c}0.0103 \\
(0.0096)\end{array}$ \\
\hline $3 r d$ & $\begin{array}{c}0.0099 \\
(0.0081)\end{array}$ & $\begin{array}{c}0.0046 \\
(0.0113)\end{array}$ & $\begin{array}{c}0.0066 \\
(0.0085)\end{array}$ & $\begin{array}{c}0.0032 \\
(0.0129)\end{array}$ & $\begin{array}{r}-0.0002 \\
(0.0042)\end{array}$ & $\begin{array}{c}0.0051 \\
(0.0075)\end{array}$ & $\begin{array}{c}0.0008 \\
(0.0045)\end{array}$ & $\begin{array}{c}0.0084 \\
(0.0084)\end{array}$ \\
\hline $\mathcal{X}^{2}($ State $)$ & & $\begin{array}{c}96.88 \\
(0.0000)\end{array}$ & & $\begin{array}{c}98.80 \\
(0.0000)\end{array}$ & & $\begin{array}{c}57.95 \\
(0.0201)\end{array}$ & & $\begin{array}{c}54.89 \\
(0.0374)\end{array}$ \\
\hline States & 43 & 43 & 43 & 43 & 43 & 39 & 43 & 39 \\
\hline Successes & 3,344 & 3,344 & 3,344 & 3,344 & 860 & 860 & 860 & 860 \\
\hline Observations & 23,117 & 23,117 & 23,117 & 23,117 & 15,237 & 15,196 & 15,237 & 15,196 \\
\hline
\end{tabular}

NOTE. Table gives probability derivatives from a probit regression of BORRSAVE(with a cutoff of $\$ 3,000$ ) against explanatory variables, including bankruptcy exemption quartiles. CE quartiles are formed from the CE sample while U.S. quartiles are formed from the U.S. states over the sample period (see text for details). Some state dummy variables predict failure perfectly; all such states are dropped for regressions using state fixed effects. For regressions without state fixed effects, standard errors are corrected for clustering; robust, cluster-adjusted, standard errors are in parentheses. 
TABLE B.3: Results of Borrowing to Save Model: $\$ 4,000$ Threshold

\begin{tabular}{|c|c|c|c|c|c|c|c|c|}
\hline & \multicolumn{8}{|c|}{ Probability Derivatives $\partial F / \partial x$} \\
\hline & \multicolumn{4}{|c|}{$\begin{array}{c}\text { Homeowners Only } \\
\text { Quartile }\end{array}$} & \multicolumn{4}{|c|}{$\begin{array}{c}\text { Renters Only } \\
\text { Quartile }\end{array}$} \\
\hline & \multicolumn{2}{|c|}{$\mathrm{CE}$} & \multicolumn{2}{|c|}{ U.S. } & \multicolumn{2}{|c|}{$\mathrm{CE}$} & \multicolumn{2}{|c|}{ U.S. } \\
\hline Top & $\begin{array}{c}0.0123 \\
(0.0106)\end{array}$ & $\begin{array}{c}0.0428 \\
(0.0189)\end{array}$ & $\begin{array}{c}0.0123 \\
(0.0108)\end{array}$ & $\begin{array}{c}0.0349 \\
(0.0189)\end{array}$ & $\begin{array}{c}0.0023 \\
(0.0032)\end{array}$ & $\begin{array}{r}-0.0000 \\
(0.0068)\end{array}$ & $\begin{array}{c}0.0029 \\
(0.0031)\end{array}$ & $\begin{array}{c}0.0061 \\
(0.0077)\end{array}$ \\
\hline 2nd & $\begin{array}{c}0.0136 \\
(0.0064)\end{array}$ & $\begin{array}{c}0.0351 \\
(0.0165)\end{array}$ & $\begin{array}{c}0.0113 \\
(0.0068)\end{array}$ & $\begin{array}{c}0.0305 \\
(0.0160)\end{array}$ & $\begin{array}{r}-0.0018 \\
(0.0028)\end{array}$ & $\begin{array}{c}0.0008 \\
(0.0058)\end{array}$ & $\begin{array}{r}-0.0040 \\
(0.0028)\end{array}$ & $\begin{array}{c}0.0024 \\
(0.0064)\end{array}$ \\
\hline $3 \mathrm{rd}$ & $\begin{array}{c}0.0036 \\
(0.0060)\end{array}$ & $\begin{array}{c}0.0175 \\
(0.0102)\end{array}$ & $\begin{array}{c}0.0018 \\
(0.0064)\end{array}$ & $\begin{array}{c}0.0170 \\
(0.0113)\end{array}$ & $\begin{array}{r}-0.0019 \\
(0.0034)\end{array}$ & $\begin{array}{c}0.0000 \\
(0.0052)\end{array}$ & $\begin{array}{r}-0.0007 \\
(0.0035)\end{array}$ & $\begin{array}{c}0.0042 \\
(0.0062)\end{array}$ \\
\hline $\mathcal{X}^{2}($ State $)$ & & 107.49 & & 106.33 & & 46.74 & & 44.24 \\
\hline $\operatorname{Pr}>\mathcal{X}^{2}$ & & 0.0000 & & 0.0000 & & 0.1309 & & 0.1924 \\
\hline States & 43 & 43 & 43 & 43 & 43 & 38 & 43 & 38 \\
\hline Successes & 2,372 & 2,372 & 2,372 & 2,372 & 578 & 578 & 578 & 578 \\
\hline Observations & 23,117 & 23,117 & 23,117 & 23,117 & 15,237 & 15,169 & 15,237 & 15,169 \\
\hline
\end{tabular}

NoTE. Table gives probability derivatives from a probit regression of BORRSAVE(with a cutoff of \$4,000) against explanatory variables, including bankruptcy exemption quartiles. CE quartiles are formed from the CE sample while U.S. quartiles are formed from the U.S. states over the sample period (see text for details). Some state dummy variables predict failure perfectly; all such states are dropped for regressions using state fixed effects. For regressions without state fixed effects, standard errors are corrected for clustering; robust, cluster-adjusted, standard errors are in parentheses. 
TABLE B.4: Results of Borrowing to Save Model: \$5,000 Threshold

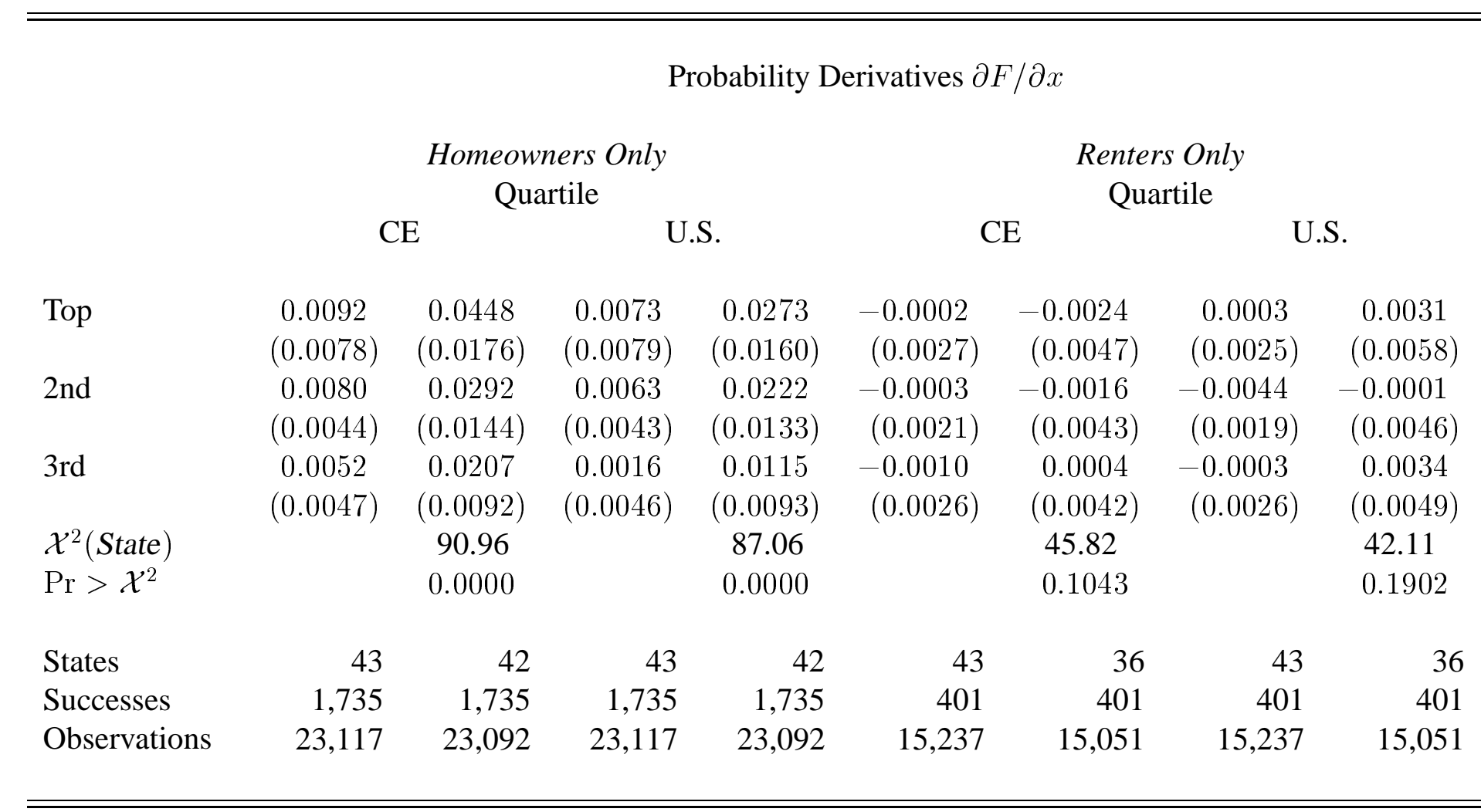

NoTE. Table gives probability derivatives from a probit regression of BORRSAVE(with a cutoff of $\$ 5,000$ ) against explanatory variables, including bankruptcy exemption quartiles. CE quartiles are formed from the CE sample while U.S. quartiles are formed from the U.S. states over the sample period (see text for details). Some state dummy variables predict failure perfectly; all such states are dropped for regressions using state fixed effects. For regressions without state fixed effects, standard errors are corrected for clustering; robust, cluster-adjusted, standard errors are in parentheses. 
TABle B.5: Probits on Pure Asset or Debt Measures

\begin{tabular}{|c|c|c|c|c|}
\hline \multirow[b]{2}{*}{ Quartile } & \multicolumn{4}{|c|}{ Threshold } \\
\hline & $\$ 2,0000$ & $\$ 3,0000$ & $\$ 4,0000$ & $\$ 5,0000$ \\
\hline & \multicolumn{4}{|c|}{ Pure Debt Measure } \\
\hline & \multicolumn{4}{|c|}{ State Fixed Effects Included } \\
\hline & \multicolumn{4}{|c|}{ Homeowners Only } \\
\hline Top Quartile........... & $\begin{array}{c}0.0237 \\
(0.0795)\end{array}$ & $\begin{array}{c}0.0386 \\
(0.0825)\end{array}$ & $\begin{array}{c}0.0179 \\
(0.0858)\end{array}$ & $\begin{array}{c}0.0441 \\
(0.0898)\end{array}$ \\
\hline \multirow{2}{*}{ Second Quartile ....... } & 0.0106 & 0.0073 & 0.0110 & -0.0106 \\
\hline & $(0.0707)$ & $(0.0735)$ & $(0.0767)$ & $(0.0804)$ \\
\hline \multirow[t]{3}{*}{ Third Quartile........ } & 0.0106 & 0.0073 & 0.0110 & -0.0106 \\
\hline & $(0.0462)$ & $(0.0481)$ & $(0.0502)$ & $(0.0528)$ \\
\hline & \multicolumn{4}{|c|}{ Renters Only } \\
\hline Top Quartile.......... & $\begin{array}{r}-0.0850 \\
(0.1017)\end{array}$ & $\begin{array}{r}-0.0224 \\
(0.1058)\end{array}$ & $\begin{array}{r}-0.0896 \\
(0.1123)\end{array}$ & $\begin{array}{r}-0.1297 \\
(0.1173)\end{array}$ \\
\hline \multirow[t]{2}{*}{ Second Quartile } & -0.0721 & -0.0175 & -0.1023 & -0.1261 \\
\hline & $(0.0856)$ & $(0.0885)$ & $(0.0941)$ & $(0.0979)$ \\
\hline \multirow[t]{3}{*}{ Third Quartile........ } & $\begin{array}{c}-0.0721 \\
(0.0766)\end{array}$ & $\begin{array}{c}-0.0175 \\
(0.0791)\end{array}$ & $\begin{array}{c}-0.1023 \\
(0.0843)\end{array}$ & $\begin{array}{c}-0.1261 \\
(0.0876)\end{array}$ \\
\hline & \multicolumn{4}{|c|}{ State Fixed Effects Included } \\
\hline & \multicolumn{4}{|c|}{ Homeowners Only } \\
\hline \multirow[t]{2}{*}{ Top Quartile.......... } & 0.0237 & 0.0386 & 0.0179 & 0.0441 \\
\hline & $(0.0795)$ & $(0.0825)$ & $(0.0858)$ & $(0.0898)$ \\
\hline \multirow[t]{3}{*}{ Second Quartile } & 0.0106 & 0.0073 & 0.0110 & -0.0106 \\
\hline & $(0.0707)$ & $(0.0735)$ & $(0.0767)$ & $(0.0804)$ \\
\hline & & & \multicolumn{2}{|c|}{ continued on next page } \\
\hline
\end{tabular}


continued from previous page

\begin{tabular}{|c|c|c|c|c|}
\hline \multirow[b]{2}{*}{ Quartile } & \multicolumn{4}{|c|}{ Threshold } \\
\hline & $\$ 2,0000$ & $\$ 3,0000$ & $\$ 4,0000$ & $\$ 5,0000$ \\
\hline \multirow[t]{2}{*}{ Third Quartile........ } & $\begin{array}{c}0.0106 \\
(0.0462)\end{array}$ & $\begin{array}{c}0.0073 \\
(0.0481)\end{array}$ & $\begin{array}{c}0.0110 \\
(0.0502)\end{array}$ & $\begin{array}{c}-0.0106 \\
(0.0528)\end{array}$ \\
\hline & \multicolumn{4}{|c|}{ Renters Only } \\
\hline Top Quartile.......... & $\begin{array}{c}-0.0850 \\
(0.1017)\end{array}$ & $\begin{array}{c}-0.0224 \\
(0.1058)\end{array}$ & $\begin{array}{c}-0.0896 \\
(0.1123)\end{array}$ & $\begin{array}{r}-0.1297 \\
(0.1173)\end{array}$ \\
\hline Second Quartile ....... & $\begin{array}{c}-0.0721 \\
(0.0856)\end{array}$ & $\begin{array}{c}-0.0175 \\
(0.0885)\end{array}$ & $\begin{array}{c}-0.1023 \\
(0.0941)\end{array}$ & $\begin{array}{c}-0.1261 \\
(0.0979)\end{array}$ \\
\hline \multirow[t]{4}{*}{ Third Quartile........ } & $\begin{array}{c}-0.0721 \\
(0.0766)\end{array}$ & $\begin{array}{c}-0.0175 \\
(0.0791)\end{array}$ & $\begin{array}{c}-0.1023 \\
(0.0843)\end{array}$ & $\begin{array}{c}-0.1261 \\
(0.0876)\end{array}$ \\
\hline & \multicolumn{4}{|c|}{ Assets Only } \\
\hline & \multicolumn{4}{|c|}{ State Fixed Effects Included } \\
\hline & \multicolumn{4}{|c|}{ Homeowners Only } \\
\hline Top Quartile.......... & $\begin{array}{c}-0.0296 \\
(0.0823)\end{array}$ & $\begin{array}{c}0.0203 \\
(0.0802)\end{array}$ & $\begin{array}{c}0.0139 \\
(0.0797)\end{array}$ & $\begin{array}{c}-0.0557 \\
(0.0798)\end{array}$ \\
\hline Second Quartile ....... & $\begin{array}{c}-0.0484 \\
(0.0721)\end{array}$ & $\begin{array}{c}-0.0056 \\
(0.0706)\end{array}$ & $\begin{array}{c}-0.0142 \\
(0.0706)\end{array}$ & $\begin{array}{c}-0.0480 \\
(0.0709)\end{array}$ \\
\hline \multirow[t]{2}{*}{ Third Quartile........ } & $\begin{array}{c}-0.0484 \\
(0.0469)\end{array}$ & $\begin{array}{c}-0.0056 \\
(0.0461)\end{array}$ & $\begin{array}{c}-0.0142 \\
(0.0463)\end{array}$ & $\begin{array}{c}-0.0480 \\
(0.0468)\end{array}$ \\
\hline & \multicolumn{4}{|c|}{ Renters Only } \\
\hline Top Quartile.......... & $\begin{array}{c}-0.0219 \\
(0.1085)\end{array}$ & $\begin{array}{c}-0.0208 \\
(0.1141)\end{array}$ & $\begin{array}{c}0.0120 \\
(0.1204)\end{array}$ & $\begin{array}{c}-0.0068 \\
(0.1237)\end{array}$ \\
\hline Second Quartile ...... & $\begin{array}{c}0.0440 \\
(0.0912)\end{array}$ & $\begin{array}{c}0.0165 \\
(0.0967)\end{array}$ & $\begin{array}{c}0.0801 \\
(0.1024)\end{array}$ & $\begin{array}{c}0.0493 \\
(0.1048)\end{array}$ \\
\hline \multirow[t]{2}{*}{ Third Quartile........ } & $\begin{array}{c}0.0440 \\
(0.0813)\end{array}$ & $\begin{array}{c}0.0165 \\
(0.0872)\end{array}$ & $\begin{array}{c}0.0801 \\
(0.0929)\end{array}$ & $\begin{array}{c}0.0493 \\
(0.0954)\end{array}$ \\
\hline & \multicolumn{4}{|c|}{ State Fixed Effects Not Included } \\
\hline
\end{tabular}


continued from previous page

\begin{tabular}{|c|c|c|c|c|}
\hline \multirow[b]{2}{*}{ Quartile } & \multicolumn{4}{|c|}{ Threshold } \\
\hline & $\$ 2,0000$ & $\$ 3,0000$ & $\$ 4,0000$ & $\$ 5,0000$ \\
\hline & \multicolumn{4}{|c|}{ Homeowners Only } \\
\hline Top Quartile.......... & $\begin{array}{c}-0.0296 \\
(0.0823)\end{array}$ & $\begin{array}{c}0.0203 \\
(0.0802)\end{array}$ & $\begin{array}{c}0.0139 \\
(0.0797)\end{array}$ & $\begin{array}{c}-0.0557 \\
(0.0798)\end{array}$ \\
\hline Second Quartile . & $\begin{array}{c}-0.0484 \\
(0.0721)\end{array}$ & $\begin{array}{r}-0.0056 \\
(0.0706)\end{array}$ & $\begin{array}{r}-0.0142 \\
(0.0706)\end{array}$ & -0.0480 \\
\hline \multirow[t]{2}{*}{ Third Quartile........ } & $\begin{array}{r}-0.0484 \\
(0.0469)\end{array}$ & $\begin{array}{c}-0.0056 \\
(0.0461)\end{array}$ & $\begin{array}{r}-0.0142 \\
(0.0463)\end{array}$ & $\begin{array}{r}-0.0480 \\
(0.0468)\end{array}$ \\
\hline & \multicolumn{4}{|c|}{ Renters Only } \\
\hline Top Quartile........... & $\begin{array}{c}-0.0219 \\
(0.1085)\end{array}$ & $\begin{array}{c}-0.0208 \\
(0.1141)\end{array}$ & $\begin{array}{c}0.0120 \\
(0.1204)\end{array}$ & $\begin{array}{c}-0.0068 \\
(0.1237)\end{array}$ \\
\hline Second Quartile ....... & $\begin{array}{c}0.0440 \\
(0.0912)\end{array}$ & $\begin{array}{c}0.0165 \\
(0.0967)\end{array}$ & $\begin{array}{c}0.0801 \\
(0.1024)\end{array}$ & $\begin{array}{c}0.0493 \\
(0.1048)\end{array}$ \\
\hline Third Quartile......... & $\begin{array}{c}0.0440 \\
(0.0813)\end{array}$ & $\begin{array}{c}0.0165 \\
(0.0872)\end{array}$ & $\begin{array}{c}0.0801 \\
(0.0929)\end{array}$ & $\begin{array}{c}0.0493 \\
(0.0954)\end{array}$ \\
\hline
\end{tabular}

NotE. Table gives coefficient estimates from probit regressions in which the dependent variable is an indicator variable set to unity if the household's unsecured debt or asset holdings exceed the indicated thresholds. The regressors include the household's bankruptcy exemption (shown) and the same set of controls used in the borrowing to save regressions (suppressed). 


\section{Potential Income Regression}

To construct our estimate of the potential income that a household could earn, we first restricted our CE sample from section 5.3 to those households who were not unemployed or too sick to work. Among the remaining households, we regressed log total household income as reported at the second interview on demographic characteristics and a set of cohort dummies. (The excluded cohort comprises those households born in or before 1929.) We also included some household characteristics, such as marital status and the number of earners. We estimated the coefficients separately for renters and homeowners. The coefficient estimates and robust standard errors are shown in table C.6. Most coefficient estimates are roughly the same for owners and renters, with the notable exception of the cohort dummies, which are well below the levels for homeowners. Presumably, being a renter despite having been born in the 1950s is associated with lower income.

Figure C.1 compares the distributions (empirical pdfs) of actual and predicted incomes. Recall that we purposely excluded all households suffering severe income shocks (unemployment or illness) from our sample, thus potential income is skewed to the right relative to actual income.

TABLE C.6: Potential Income Regressions

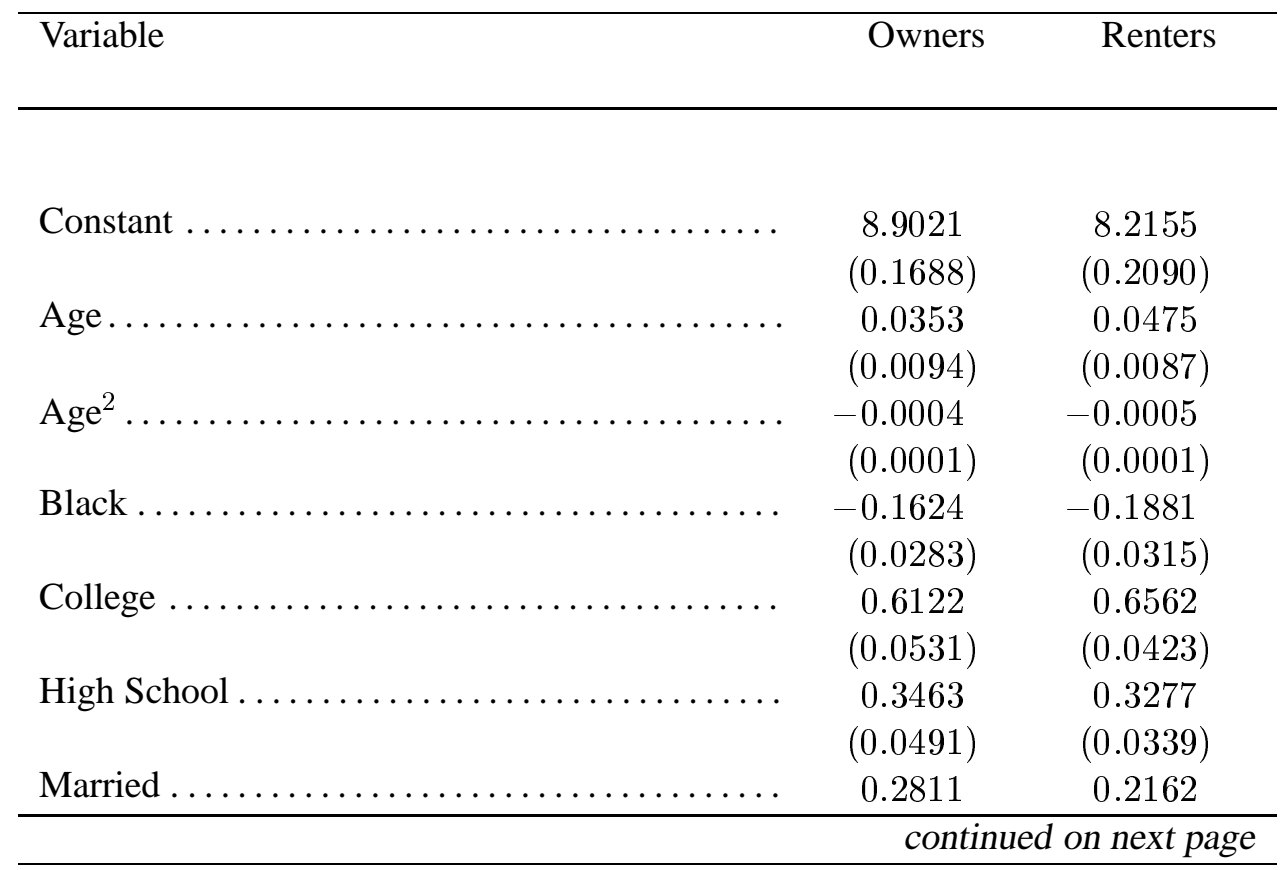




\begin{tabular}{|c|c|c|}
\hline Variable & Owners & Renters \\
\hline Number of Earners ... & $\begin{array}{c}(0.0170) \\
0.2058 \\
(0.0114)\end{array}$ & $\begin{array}{c}(0.0230) \\
0.3518 \\
(0.0154)\end{array}$ \\
\hline \multicolumn{3}{|l|}{ Cohort Dummy Variables } \\
\hline Cohort $2(1930 \leq$ Year Born $\leq 1939) \ldots \ldots \ldots \ldots$ & $\begin{array}{c}0.0552 \\
(0.0368)\end{array}$ & $\begin{array}{c}-0.1126 \\
(0.0666)\end{array}$ \\
\hline Cohort $3(1940 \leq$ Year Born $\leq 1949) \ldots \ldots \ldots \ldots$ & $\begin{array}{c}0.0547 \\
(0.0488)\end{array}$ & $\begin{array}{c}-0.0381 \\
(0.0901)\end{array}$ \\
\hline Cohort $4(1950 \leq$ Year Born $\leq 1959) \ldots \ldots \ldots \ldots$ & $\begin{array}{c}0.1302 \\
(0.0629)\end{array}$ & $\begin{array}{c}0.0150 \\
(0.0987)\end{array}$ \\
\hline Cohort $5(1960 \leq$ Year Born $\leq 1969) \ldots$ & $\begin{array}{c}0.1264 \\
(0.0749)\end{array}$ & $\begin{array}{c}0.0344 \\
(0.1158)\end{array}$ \\
\hline Cohort 6 (Year Born $\geq 1970)$. . & $\begin{array}{c}-0.0150 \\
(0.0900)\end{array}$ & $\begin{array}{r}-0.0461 \\
(0.1310)\end{array}$ \\
\hline $\mathrm{R}^{2}$. & 0.2652 & 0.3062 \\
\hline Observations. . & 9,000 & 5,235 \\
\hline
\end{tabular}

NoTE. Table gives regression results of log of second interview income on explanatory variables; robust, cluster-adjusted standard errors are in parentheses. Regression excluded all households involuntarily unemployed or too sick to work. 
FIGURE C.1: Actual and estimated potential income
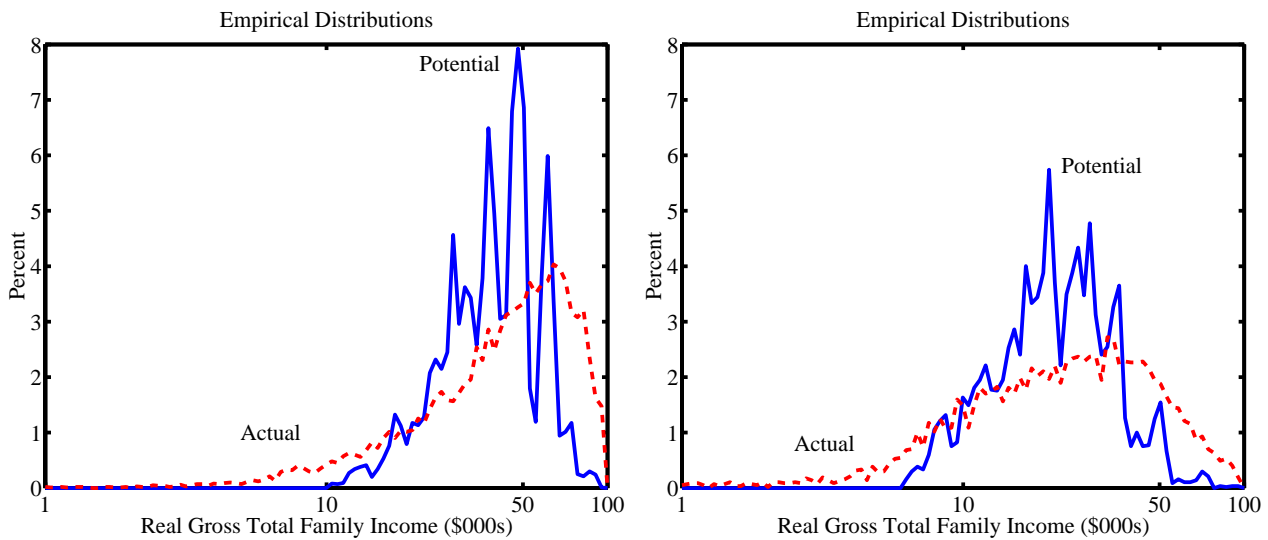

(a) Home Owners

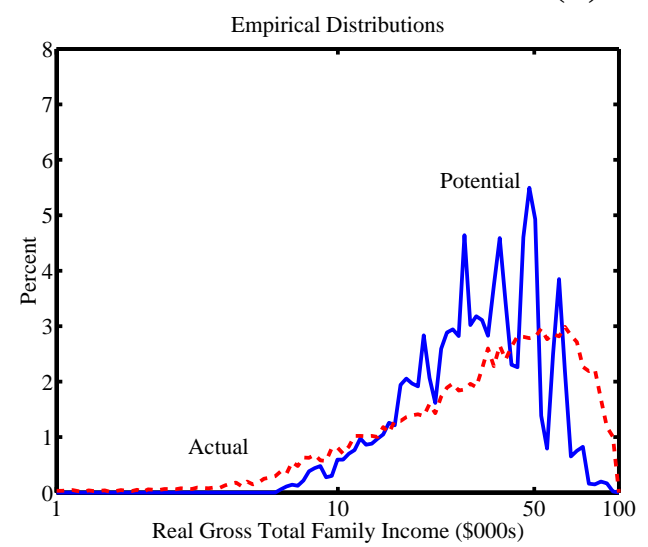

(c) All

Note. Figures give the probability distributions (pdfs) of actual and estimated potential total gross household family income. The regressions used to produce potential income are shown in appendix $\mathrm{C}$. 


\section{References}

Alexopoulos, M. and I. Domowitz (1998). Personal liabilities and bankruptcy reform: An international perspective. International Finance 1(1), 127-159.

Baird, D. G. and E. R. Morrison (2001, June). Bankruptcy decision making. University of Chicago, John M. Olin Law \& Economics Working Paper Series \#126; forthcoming Journal of Law, Economics and Organization.

Bertaut, C. C. and M. Haliassos (2001). Debt revolvers for self-control. Manuscript, Federal Reserve Board, Washington, D.C.

Carroll, C. D. (1992). Buffer stock saving: Some macroeconomic evidence. Brookings Papers on Economic Activity 1992(2), 61-156.

Carroll, C. D. (1994, February). How does future income affect current consumption? Quarterly Journal of Economics 109(1), 111-47.

Carroll, C. D. and A. A. Samwick (1998). How important is precautionary saving? Review of Economics and Statistics 80(3), 410-19.

Deaton, A. (1990). Saving in developing countries: Theory and review. In Proceedings of the World Bank Annual Conference on Develo pment Economics 1989. The World Bank.

Denning, K. C., S. P. Ferris, and R. M. Lawless (2001, February). Serial bankruptcy: Plan infeasibility or just bad luck? Applied Economics Letters 8(2), 105-109.

Domowitz, I. and R. L. Sartain (1999). Determinants of the consumer bankruptcy decision. Journal of Finance 54(1), 403-20.

Durkin, T. A. (2000). Credit cards: Use and consumer attitudes, 1970-2000. Federal Reserve Bulletin 86(1), 623-634.

Dynan, K. and D. M. Maki (2001). Does stock market wealth matter for consumption? Finance and Economics Discussion Series 2001-23, Federal Reserve Board.

Elul, R. and N. Subramanian (1999). Forum-shopping and personal bankruptcy. Brown University Working Paper \#99-1.

Engen, E. (1993). Consumption and saving in a life-cycle model with stochastic earnings and uncertain lifespan. Manuscript, Federal Reserve Board, Washington D.C. 
Fay, S., E. Hurst, and M. White (1998, January). The bankruptcy decision: Does stigma matter? Department of Economics Working Paper 98-01, University of Michigan.

Gropp, R., J. K. Scholz, and M. J. White (1997). Personal bankruptcy and credit supply and demand. Quarterly Journal of Economics 112(1), 217-51.

Gross, D. B. and N. S. Souleles (1998). Explaining the increase in bankruptcy and delinquency: Stigma versus risk-composition. The Wharton School, University of Pennsylvania.

Gross, K. (1997). Failure and Forgiveness: Rebalancing the Bankruptcy System. New Haven, CT: Yale University Press.

Harris, C. and D. Laibson (2001, July). Dynamic choices of hyperbolic consumers. Econometrica 69(4), 935-57.

Hubbard, R. G., J. Skinner, and S. P. Zeldes (1994, May). Expanding the lifecycle model: Precautionary saving and public policy. American Economic Review 84(2), 174-79.

Hynes, R. (1998). Three Essays on Exemptions and Consumer Bankruptcy. $\mathrm{Ph}$. D. thesis, University of Pennsylvania.

Kennickell, A. B., M. Starr-McCluer, and B. J. Surrette (2000). Recent changes in U.S. family finances: Results from the 1998 Survey of Consumer Finances. Federal Reserve Bulletin 86(1), 1-29.

Laibson, D. I., A. Repetto, and J. Tobacman (1998). Self-control and saving for retirement. Brookings Papers on Economic Activity 1998(1), 91-172.

Lehnert, A. and D. M. Maki (2000). The great American debtor. Manuscript, Federal Reserve Board of Governors, Washington, DC.

Morrison, A. K. M. (1999). Two Essays on Consumer Credit. Ph. D. thesis, University of Chicago.

Mulligan, J. V. (2001, May). The impact of state exemptions on personal bankruptcy filings. MA thesis, Virginia Polytechnical Institute.

Nelson, J. P. (1999). Consumer bankruptcy and chapter choice: State panel evidence. Contemporary Economic Policy 17(4), 552-566.

Nelson, J. P. (2000). Consumer bankruptcies and the bankruptcy reform act: A time-series intervention analysis, 1960-1997. Journal of Financial Services Research 17(4), 181-200. 
Olney, M. L. (1999). Avoiding default: The role of credit in the consumption collapse of the 1930s. Quarterly Journal of Economics 114(1), 319-35.

Parker, J. A. (1999, September). The reaction of household consumption to predictable changes in social security taxes. American Economic Review 89(4), 959-73.

Pence, K. (2001). Foreclosing on opportunity? State laws and mortgage credit. Manuscript, Federal Reserve Board, Washington DC.

Poterba, J. M. (1991). House price dynamics: The role of tax policy and demography. Brookings Papers on Economic Activity 0(2), 143-83.

Souleles, N. (1999, September). The response of household consumption to income tax refunds. American Economic Review 89(4), 947-58.

Sullivan, J. X. (2002). Borrowing during unemployment: Unsecured debt as a safety net. Department of Economics, Northwestern University, Evanston IL.

Sullivan, T. A., E. Warren, and J. L. Westbrook (1989). As We Forgive Our Debtors: Bankruptcy and Consumer Credit in America. New York, NY: Oxford University Press.

Sullivan, T. A., E. Warren, and J. L. Westbrook (1997). Consumer bankruptcy in the United States: A survey of alleged abuse and of local legal culture. Journal of Consumer Policy 20(2), 223-68.

Visa U.S.A. Inc. (1998, September). 1997 Annual Bankruptcy Survey. Visa consumer bankruptcy reports, Visa U.S.A. Inc.

White, M. (1998, March). Why don't more households file for bankruptcy. Department of Economics Working Paper 98-03, University of Michigan.

White, M. J. (1987). Personal bankruptcy under the 1978 bankruptcy code: An economic analysis. Indiana Law Journal 63(1), 1-57.

Williamson, J. H. (1999). The Attorney's Handbook on Consumer Bankruptcy and Chapter 13. Lakewood, Colorado: Argyle Publishing Company.

Zeldes, S. P. (1989a, April). Consumption and liquidity constraints: An empirical investigation. Journal of Political Economy 97(2), 305-46.

Zeldes, S. P. (1989b, May). Optimal consumption with stochastic income: Deviations from certainty equivalence. Quarterly Journal of Economics 104(2), 275-98. 
Ziegel, J. S. (1997). Canadian perspectives on the challenges of consumer bankruptcies. Journal of Consumer Policy 20(2), 199-221. 
TABLE 1: State-level Sample Means U.S. Quartile Rank

Variable

Bot. 3rd 2nd Top

\section{Married Homeowners}

\begin{tabular}{|c|c|c|c|c|}
\hline Exemption $^{a}$. & $\begin{array}{r}24,580 \\
(4,471)\end{array}$ & $\begin{array}{l}40,648 \\
(7,802)\end{array}$ & $\begin{array}{r}91,779 \\
(20,222)\end{array}$ & $\begin{array}{l}212,703 \\
(90,140)\end{array}$ \\
\hline Chapter 7 Rate .. & $\begin{array}{c}0.22 \\
(0.11)\end{array}$ & $\begin{array}{c}0.18 \\
(0.11)\end{array}$ & $\begin{array}{c}0.22 \\
(0.11)\end{array}$ & $\begin{array}{c}0.23 \\
(0.12)\end{array}$ \\
\hline Income growth & $\begin{array}{c}2.46 \\
(2.15)\end{array}$ & $\begin{array}{c}2.91 \\
(2.42)\end{array}$ & $\begin{array}{c}2.34 \\
(2.39)\end{array}$ & $\begin{array}{c}2.43 \\
(3.58)\end{array}$ \\
\hline Unemployment rate. . & $\begin{array}{c}5.65 \\
(1.95)\end{array}$ & $\begin{array}{c}6.13 \\
(1.75)\end{array}$ & $\begin{array}{c}6.15 \\
(1.98)\end{array}$ & $\begin{array}{c}5.33 \\
(1.56)\end{array}$ \\
\hline House price growth & $\begin{array}{c}1.37 \\
(3.98)\end{array}$ & $\begin{array}{c}2.41 \\
(5.50)\end{array}$ & $\begin{array}{c}1.79 \\
(5.97)\end{array}$ & $\begin{array}{c}0.54 \\
(4.50)\end{array}$ \\
\hline & \multicolumn{4}{|c|}{ Single Renters } \\
\hline Exemption... & $\begin{array}{r}5,201 \\
(1,258)\end{array}$ & $\begin{array}{r}8,676 \\
(1,089)\end{array}$ & $\begin{array}{r}12,928 \\
(1,583)\end{array}$ & $\begin{array}{l}23,696 \\
(9,113)\end{array}$ \\
\hline Chapter 7 Rate. & $\begin{array}{c}0.23 \\
(0.10)\end{array}$ & $\begin{array}{c}0.17 \\
(0.11)\end{array}$ & $\begin{array}{c}0.22 \\
(0.12)\end{array}$ & $\begin{array}{c}0.23 \\
(0.12)\end{array}$ \\
\hline Income growth & $\begin{array}{c}2.54 \\
(2.53)\end{array}$ & $\begin{array}{c}2.68 \\
(3.56)\end{array}$ & $\begin{array}{c}2.45 \\
(2.16)\end{array}$ & $\begin{array}{c}2.47 \\
(2.30)\end{array}$ \\
\hline Unemployment rate. & $\begin{array}{c}5.40 \\
(1.73)\end{array}$ & $\begin{array}{c}6.09 \\
(2.00)\end{array}$ & $\begin{array}{c}6.09 \\
(1.70)\end{array}$ & $\begin{array}{c}5.66 \\
(1.86)\end{array}$ \\
\hline House price growth & $\begin{array}{c}1.69 \\
(3.57)\end{array}$ & $\begin{array}{c}1.71 \\
(6.45)\end{array}$ & $\begin{array}{c}1.84 \\
(4.96)\end{array}$ & $\begin{array}{c}0.88 \\
(4.89)\end{array}$ \\
\hline
\end{tabular}

Note. Table gives sample means and standard deviations from a sample of 51 states over the 16 years 1984-1999, conditional on the state's exemption quartile. Note that states switch quartiles, so that any one state's data may be present in the results for many different quartiles.

\footnotetext{
${ }^{a}$ For states with finite exemptions only.
} 
TABLE 2: Relation of U.S. quartiles

Single Homeowners Bottom 3rd 2nd Top

Married Homeowners

$\begin{array}{lrrrrlrrrr}\text { Bottom } & 189 & 15 & 0 & 0 & \text { Bottom } & 105 & 60 & 38 & 1 \\ \text { 3rd } & 15 & 169 & 20 & 0 & \text { 3rd } & 40 & 85 & 51 & 28 \\ \text { 2nd } & 0 & 12 & 170 & 21 & \text { 2nd } & 13 & 38 & 60 & 92 \\ \text { Top } & 0 & 8 & 13 & 184 & \text { Top } & 46 & 25 & 52 & 82\end{array}$

NOTE. Table gives cross-tabulations of U.S. quartiles. Note that the quartiles for single and married homeowners are quite similar, while those for married homeowners and single renters (the two largest groups of debtors) are very different. 
TABLE 3: Separate Effects of Bankruptcy Law on Chapter 7 Bankruptcy Rates

\begin{tabular}{lcccc}
\hline \hline & \multicolumn{4}{c}{ Exemptions } \\
\cline { 2 - 5 } & \multicolumn{2}{c}{ Homeowners } & \multicolumn{2}{c}{ Renters } \\
Married & Single & Married & Single \\
Variable & & & & \\
& & & & \\
Top quartile ......... & 0.4988 & 0.1506 & 0.1472 & 0.1575 \\
& $(0.0557)$ & $(0.0561)$ & $(0.0502)$ & $(0.0473)$ \\
2nd quartile ......... & 0.3257 & 0.2968 & 0.1179 & 0.1321 \\
& $(0.0466)$ & $(0.0413)$ & $(0.0499)$ & $(0.0459)$ \\
3rd quartile ......... & 0.0941 & 0.0904 & 0.0255 & 0.0209 \\
& $(0.0285)$ & $(0.0266)$ & $(0.0414)$ & $(0.0408)$ \\
Income growth ${ }^{a} \ldots . .$. & -0.0048 & -0.0016 & -0.0061 & -0.0054 \\
& $(0.0046)$ & $(0.0039)$ & $(0.0046)$ & $(0.0045)$ \\
Unemployment Rate . & 0.0766 & 0.0805 & 0.0781 & 0.0801 \\
& $(0.0108)$ & $(0.0099)$ & $(0.0111)$ & $(0.0110)$ \\
House-price growth ... & -0.0069 & -0.0085 & -0.0065 & -0.0063 \\
& $(0.0027)$ & $(0.0023)$ & $(0.0030)$ & $(0.0030)$ \\
& & & & \\
$F(\text { State })^{b}$ & 134.54 & 137.87 & 122.97 & 123.84 \\
$F\left(\right.$ Year ${ }^{c}$ & 141.96 & 186.89 & 140.71 & 142.79 \\
& & & & \\
\hline \hline
\end{tabular}

NOTE. Table gives coefficient estimates from estimating equation (11) using data from 51 states from 1984-1999; robust standard errors are in parentheses.

\footnotetext{
${ }^{a}$ State average real per-capita income growth.

${ }^{b} F$-test statistic of hypothesis that all state dummies are jointly equal to zero.

${ }^{c} F$-test statistic of hypothesis that all year dummies are jointly equal to zero.
} 
TABLE 4: Joint Effect of Homeowner and Renter Exemptions Coefficient Robust Estimate Std. Err.

Variable

Married Homeowner Quartiles

\begin{tabular}{|c|c|}
\hline Top . & 0.4540 \\
\hline $2 \mathrm{nd}$ & 0.2856 \\
\hline d & 0.0803 \\
\hline
\end{tabular}

Single Renter Quartiles

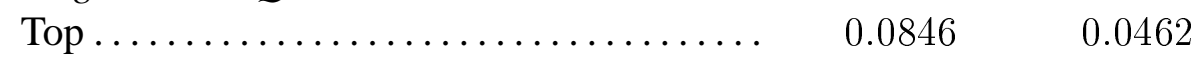

2nd .......................... $0.0665 \quad 0.0451$

3rd.............................. $0.0310 \quad 0.0376$

Real per-capita income growth.......... $-0.0053 \quad 0.0043$

Unemployment rate ................. $0.0785 \quad 0.0106$

Real house-price growth ............ $-0.0064 \quad 0.0028$

$F(\text { State })^{a} \ldots \ldots \ldots \ldots \ldots \ldots \ldots \ldots \ldots \ldots \ldots \ldots \ldots$

$F(\text { Year })^{b} \ldots \ldots \ldots \ldots \ldots \ldots \ldots \ldots \ldots \ldots \ldots \ldots \ldots$

NOTE. Table gives coefficient estimates and robust standard errors from a weighted least squares regression of Chapter 7 bankruptcy rates on the U.S. quartile dummies for both married homeowners and single renters (the two largest groups of bankruptcy filers).

${ }^{a} F$-test statistic of hypothesis that all state dummies are jointly equal to zero.

${ }^{b} F$-test statistic of hypothesis that all state dummies are jointly equal to zero. 
TABLE 5: Sample means from CE portfolio database

Tenure

All Rent Own

Variable

Age

$45 \quad 40$

49

(16)

(13)

Family size

2.74

2.48

(1.57) (1.60)

-Real 1996-

Unsecured debt

$3,081 \quad 2,408$

3,525

$(6,720) \quad(6,031)$

$(7,103)$

Liquid assets

$8,446 \quad 3,727 \quad 11,556$

$(15,897) \quad(10,176) \quad(18,073)$

Gross total family income (annual) .....

$\begin{array}{lll}45,369 & 29,695 & 55,700\end{array}$

$(36,391) \quad(23,791) \quad(39,407)$

-Percent-

Married.........................

Black...........................

$13 \quad 20$

High school graduate ...............

$54 \quad 55$

54

College graduate. .

Borrowing to save (various thresholds)

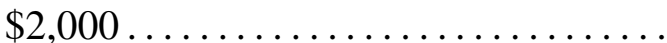

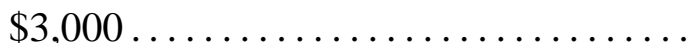

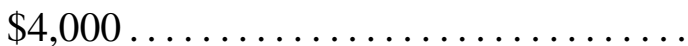

16.0

8.9

20.7

$\$ 5,000$

11.0

$5.6 \quad 14.5$

$\begin{array}{lll}7.7 & 3.8 & 10.3\end{array}$

$\begin{array}{lll}7.6 & 2.6 & 7.5\end{array}$

\begin{tabular}{llrr} 
Observations $\ldots \ldots \ldots \ldots \ldots \ldots \ldots \ldots$ & 38,354 & 15,237 & 23,117 \\
\hline
\end{tabular}

NOTE. Table gives sample means from the subset of the CE used in estimating the propensity of borrowing to save in section 5.2 of the text. See appendix A.4 for the construction of this dataset. 
TABLE 6: Selected results from the borrowing to save model

Probability Derivatives $\partial F / \partial x$

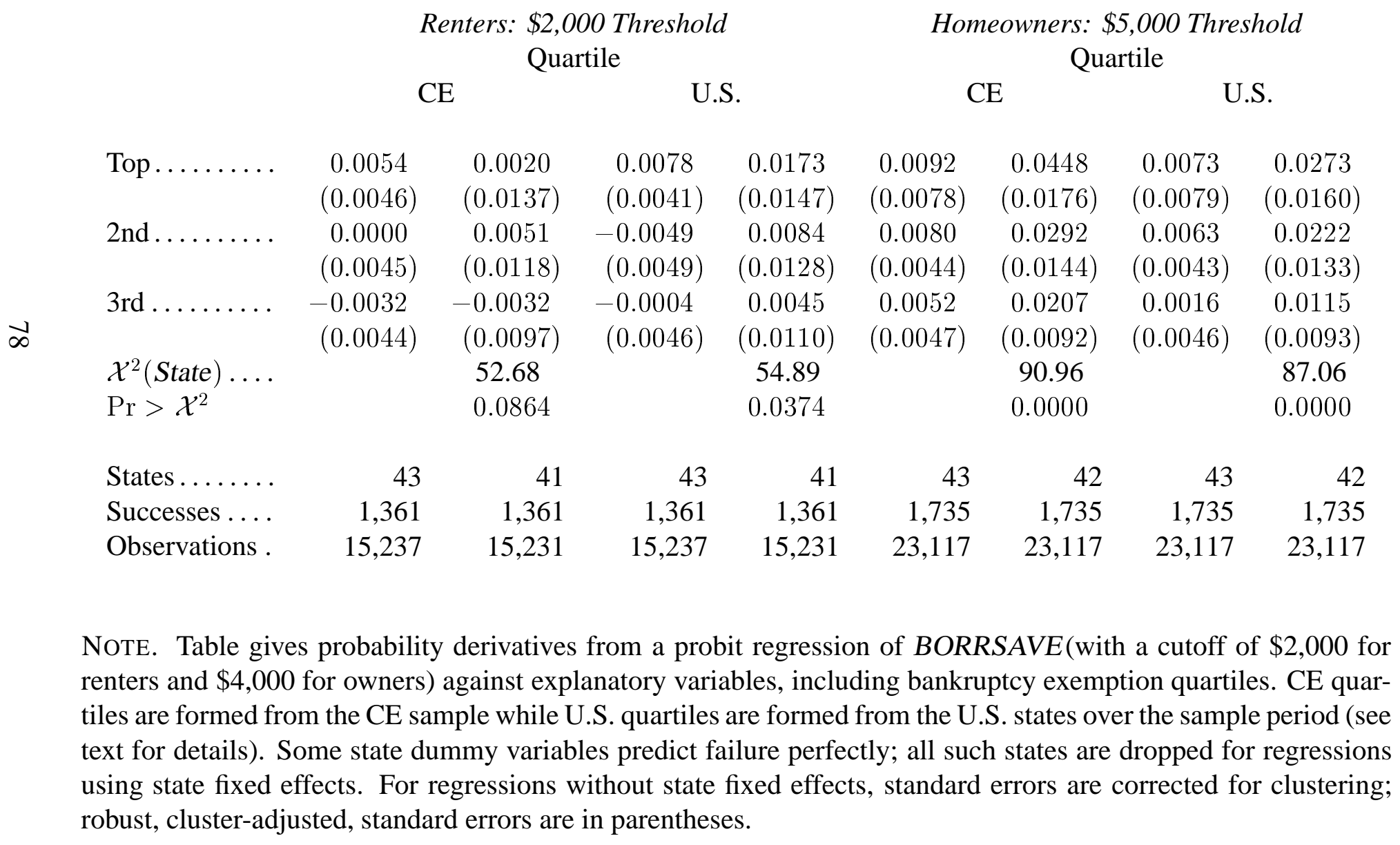


TABLE 7: Sample means by debt status for the insurance model

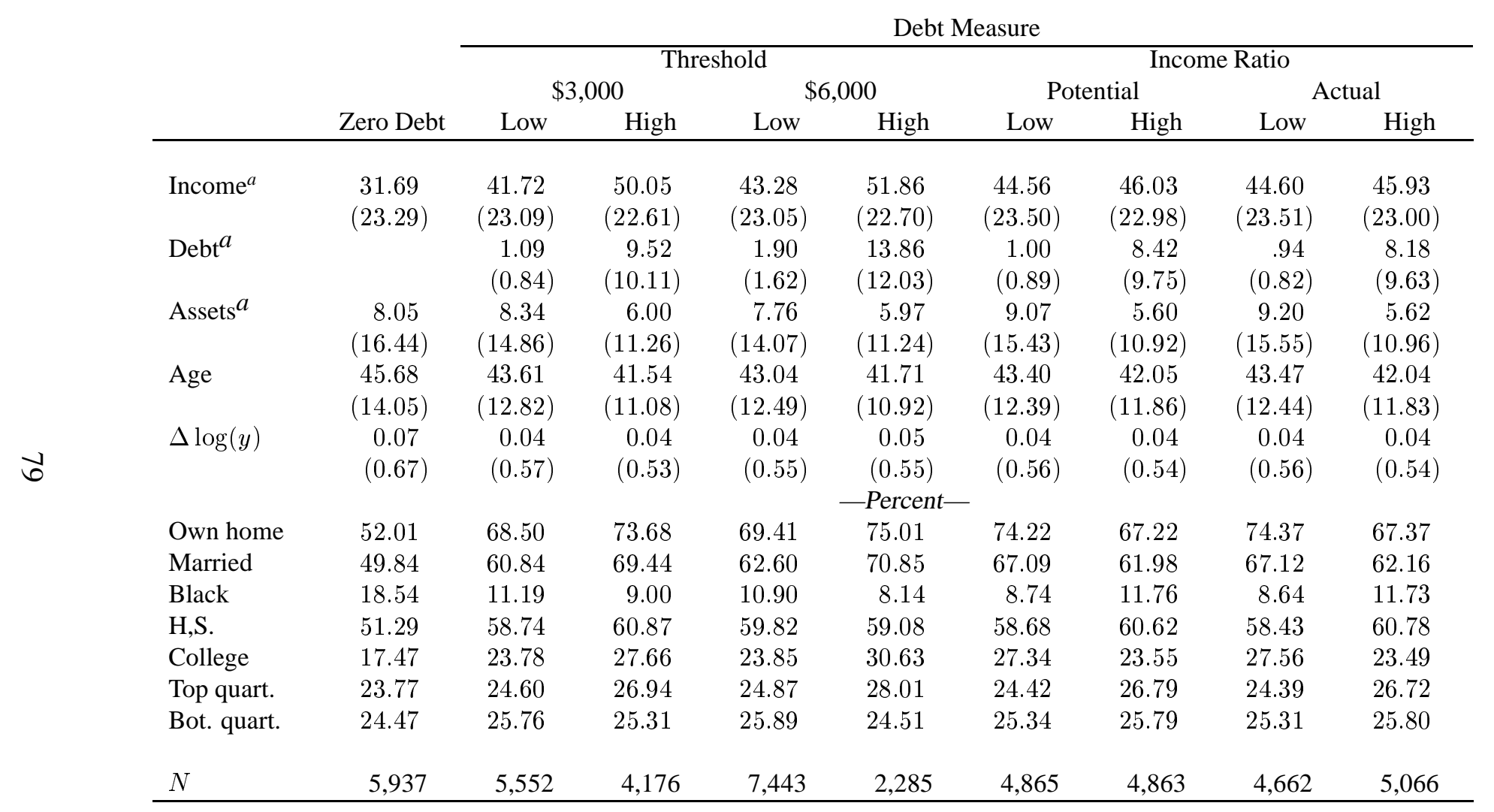

NOTE. Table gives sample means and standard deviations for zero-debt, low-debt and high-debt households, using three different definitions of high debt. See text for details. Assets are liquid assets at fifth interview and debts are unsecured debts at second interview.

${ }^{a}$ Real 1996, \$000s 
TABLE 8: $\Delta \log (c)$ by debt and bankruptcy exemption using threshold measures of debt.

Owners

Renters

\section{\$3,000 Threshold Debt Measure}

\begin{tabular}{|c|c|c|c|c|c|c|c|c|}
\hline \multirow[b]{2}{*}{ Debt } & \multicolumn{4}{|c|}{ Asset Exemption Quartile } & \multicolumn{4}{|c|}{ Asset Exemption Quartile } \\
\hline & Bottom & $3 \mathrm{rd}$ & 2nd & Top & Bottom & $3 \mathrm{rd}$ & 2nd & Top \\
\hline Zero & $\begin{array}{c}0.0140 \\
(0.2948)\end{array}$ & $\begin{array}{c}-0.0128 \\
(0.3010)\end{array}$ & $\begin{array}{r}-0.0093 \\
(0.2845)\end{array}$ & $\begin{array}{c}-0.0111 \\
(0.3049)\end{array}$ & $\begin{array}{c}0.0055 \\
(0.3153)\end{array}$ & $\begin{array}{c}0.0149 \\
(0.3404)\end{array}$ & $\begin{array}{c}0.0076 \\
(0.3086)\end{array}$ & $\begin{array}{c}0.0244 \\
(0.3278)\end{array}$ \\
\hline Low & $\begin{array}{r}-0.0049 \\
(0.2611)\end{array}$ & $\begin{array}{r}-0.0099 \\
(0.2745)\end{array}$ & $\begin{array}{r}-0.0207 \\
(0.2746)\end{array}$ & $\begin{array}{r}-0.0047 \\
(0.2853)\end{array}$ & $\begin{array}{r}-0.0136 \\
(0.2888)\end{array}$ & $\begin{array}{c}-0.0055 \\
(0.3026)\end{array}$ & $\begin{array}{r}-0.0324 \\
(0.2915)\end{array}$ & $\begin{array}{r}-0.0057 \\
(0.2965)\end{array}$ \\
\hline High & $\begin{array}{r}-0.0098 \\
(0.2620)\end{array}$ & $\begin{array}{r}-0.0097 \\
(0.2724)\end{array}$ & $\begin{array}{r}-0.0080 \\
(0.2639)\end{array}$ & $\begin{array}{c}-0.0222 \\
(0.2661)\end{array}$ & $\begin{array}{c}0.0040 \\
(0.2849)\end{array}$ & $\begin{array}{c}-0.0131 \\
(0.2697)\end{array}$ & $\begin{array}{c}0.0063 \\
(0.2797)\end{array}$ & $\begin{array}{c}0.0136 \\
(0.3124)\end{array}$ \\
\hline
\end{tabular}

\section{\$6,000 Threshold Debt Measure}

\begin{tabular}{ccccccccc} 
& \multicolumn{3}{c}{ Asset Exemption Quartile } & \multicolumn{3}{c}{ Asset Exemption Quartile } \\
& Bottom & 3rd & 2nd & Top & Bottom & 3rd & 2nd & Top \\
Debt & & & & & & & & \\
Zero & 0.0140 & -0.0128 & -0.0093 & -0.0111 & 0.0055 & 0.0149 & 0.0076 & 0.0244 \\
& $(0.2948)$ & $(0.3010)$ & $(0.2845)$ & $(0.3049)$ & $(0.3153)$ & $(0.3404)$ & $(0.3086)$ & $(0.3278)$ \\
Low & -0.0076 & -0.0152 & -0.0168 & -0.0076 & -0.0052 & -0.0077 & -0.0326 & 0.0048 \\
& $(0.2619)$ & $(0.2710)$ & $(0.2718)$ & $(0.2842)$ & $(0.2899)$ & $(0.3010)$ & $(0.2900)$ & $(0.2980)$ \\
High & -0.0054 & 0.0082 & -0.0089 & -0.0272 & -0.0141 & -0.0110 & 0.0485 & -0.0044 \\
& $(0.2602)$ & $(0.2815)$ & $(0.2635)$ & $(0.2542)$ & $(0.2770)$ & $(0.2423)$ & $(0.2673)$ & $(0.3204)$
\end{tabular}

NoTE. Table gives means and standard deviations (in parentheses) for the log difference in non-durable consumption from the second to the fifth interviews of the CE depending on (1) the household's debt status and (2) the quartile bankruptcy exemption rank of the state-year in which the household resides. 
TABLE 9: $\Delta \log (c)$ by debt and bankruptcy exemption.

\begin{tabular}{cccc}
\multicolumn{3}{c}{ Asset Exemption Quartile } \\
Bottom & 3rd & 2nd & Top
\end{tabular}

Homeowners

Debt Status

\begin{tabular}{llcccc}
\hline Zero & $d=0$ & 0.0140 & -0.0128 & -0.0093 & -0.0111 \\
& & $(0.2948)$ & $(0.3010)$ & $(0.2845)$ & $(0.3049)$ \\
Low & $d / \widehat{y} \leq 6.4 \%$ & -0.0021 & -0.0084 & -0.0203 & -0.0034 \\
& & $(0.2596)$ & $(0.2705)$ & $(0.2691)$ & $(0.2890)$ \\
High & $d / \widehat{y}>6.4 \%$ & -0.0125 & -0.0116 & -0.0089 & -0.0225 \\
& & $(0.2634)$ & $(0.2775)$ & $(0.2702)$ & $(0.2631)$
\end{tabular}

\begin{tabular}{llcccc} 
Debt Status & & & & & \\
\cline { 1 - 4 } Zero & $d=0$ & 0.0055 & 0.0149 & 0.0076 & 0.0244 \\
& & $(0.3153)$ & $(0.3404)$ & $(0.3086)$ & $(0.3278)$ \\
Low & $d / \widehat{y} \leq 6.4 \%$ & -0.0035 & -0.0062 & -0.0409 & 0.0019 \\
& & $(0.2874)$ & $(0.3064)$ & $(0.2951)$ & $(0.2995)$ \\
High & $d / \widehat{y}>6.4 \%$ & -0.0096 & -0.0101 & 0.0012 & 0.0030 \\
& & $(0.2875)$ & $(0.2768)$ & $(0.2801)$ & $(0.3063)$
\end{tabular}

NOTE. Table gives means and standard deviations (in parentheses) for the log difference in non-durable consumption from the second to the fifth interviews of the CE depending on (1) the household's debt status and (2) the quartile bankruptcy exemption rank of the state-year in which the household resides. 
TABLE 10: Distribution of observations by debt and bankruptcy law status.

\begin{tabular}{|c|c|c|c|c|c|c|c|c|}
\hline & \multicolumn{4}{|c|}{ Owners } & \multicolumn{4}{|c|}{ Renters } \\
\hline & \multicolumn{4}{|c|}{ Quartile } & \multicolumn{4}{|c|}{ Quartile } \\
\hline & Bot. & $3 \mathrm{rd}$ & 2nd & Top & Bot. & $3 r d$ & $2 \mathrm{nd}$ & Top \\
\hline Zero & 778 & 783 & 782 & 745 & 675 & 785 & 723 & 666 \\
\hline Low & 911 & 949 & 875 & 876 & 322 & 307 & 313 & 312 \\
\hline High & 835 & 748 & 840 & 846 & 419 & 345 & 373 & 457 \\
\hline
\end{tabular}

NOTE. Table gives number of observations in each combination of debt status and bankruptcy exemption quartile. Here we use the ratio of debt to potential income as our debt status measure. 
TABLE 11: Test for Olney Effects

Owners

\begin{tabular}{|c|c|c|c|c|c|c|c|}
\hline & & \\
\hline & & Zero & Low & High & Zero & Low & High \\
\hline & $\gamma^{T o p}$ & $\begin{array}{c}0.0358 \\
(0.0222)\end{array}$ & $\begin{array}{c}0.0507 \\
(0.0183)\end{array}$ & $\begin{array}{c}0.0426 \\
(0.0188)\end{array}$ & $\begin{array}{r}-0.0087 \\
(0.0207)\end{array}$ & $\begin{array}{c}0.0101 \\
(0.0255)\end{array}$ & $\begin{array}{r}0.0417 \\
(0.0223)\end{array}$ \\
\hline & \multirow[t]{2}{*}{$\gamma^{2 n d}$} & 0.0646 & 0.0463 & 0.0181 & -0.0060 & 0.0279 & 0.0025 \\
\hline & & $(0.0163)$ & $(0.0195)$ & $(0.0278)$ & $(0.0171)$ & $(0.0364)$ & $(0.0322)$ \\
\hline & \multirow[t]{2}{*}{$\gamma^{3 r d}$} & 0.0234 & 0.0349 & 0.0218 & 0.0768 & 0.0326 & 0.0309 \\
\hline & & $(0.0135)$ & $(0.0170)$ & $(0.0207)$ & $(0.0199)$ & $(0.0289)$ & $(0.0321)$ \\
\hline & \multirow[t]{2}{*}{$\gamma^{\text {Bottom }}$} & 0.0598 & 0.0127 & 0.0037 & 0.0028 & 0.0703 & 0.0468 \\
\hline & & $(0.0198)$ & $(0.0160)$ & $(0.0209)$ & $(0.0220)$ & $(0.0236)$ & $(0.0217)$ \\
\hline & \multirow[t]{2}{*}{$b^{\text {Top }}$} & -0.1489 & -0.1522 & -0.0758 & -0.0462 & 0.3851 & -0.0993 \\
\hline & & $(0.1103)$ & $(0.1021)$ & $(0.1192)$ & $(0.1098)$ & $(0.1462)$ & $(0.1230)$ \\
\hline & \multirow[t]{2}{*}{$b^{2 \mathrm{nd}}$} & -0.1594 & -0.1501 & -0.0822 & -0.0743 & 0.3695 & -0.0966 \\
\hline g & & $(0.1052)$ & $(0.0988)$ & $(0.1159)$ & $(0.1064)$ & $(0.1425)$ & $(0.1235)$ \\
\hline & \multirow[t]{2}{*}{$b^{3 r d}$} & -0.1023 & -0.1177 & -0.1247 & -0.0728 & 0.4725 & -0.1189 \\
\hline & & $(0.0996)$ & $(0.0947)$ & $(0.1132)$ & $(0.1088)$ & $(0.1459)$ & $(0.1293)$ \\
\hline & \multirow[t]{2}{*}{$b^{\text {Bottom }}$} & -0.0660 & -0.1118 & -0.1291 & -0.1004 & 0.5262 & -0.1019 \\
\hline & & $(0.1040)$ & $(0.0975)$ & $(0.1152)$ & $(0.1180)$ & $(0.1554)$ & $(0.1401)$ \\
\hline & $F($ State $)$ & 2.05 & 1.23 & 2.50 & 3.76 & 3.07 & 2.12 \\
\hline & Prob $>F$ & $(0.0001)$ & 0.1471 & $(0.0000)$ & $(0.0000)$ & $(0.0000)$ & $(0.0001)$ \\
\hline & Observations & 3,088 & 3,611 & 3,269 & 2,849 & 1,254 & 1,594 \\
\hline
\end{tabular}

NOTE. Table gives selected regression coefficients and robust standard errors from estimating equation (13) under the indicated subsets of the data. The dependent variable in all cases is log consumption growth; the $\gamma$ parameters give the coefficient on log income growth interacted with bankruptcy generosity quartile, the $b$ parameters give the intercepts (the constant is suppressed).

Here low debt is defined as having positive debt, but below the median debt to potential income ratio in the sample. Those households with debt to potential income ratios above the median among those households with positive debt are classed as high debt. Only those households with exactly zero unsecured debt are classed as zero debt. 
FIGURE 1: Contrasting an interior optimal choice of assets and debt with a maximal-borrowing strategy.

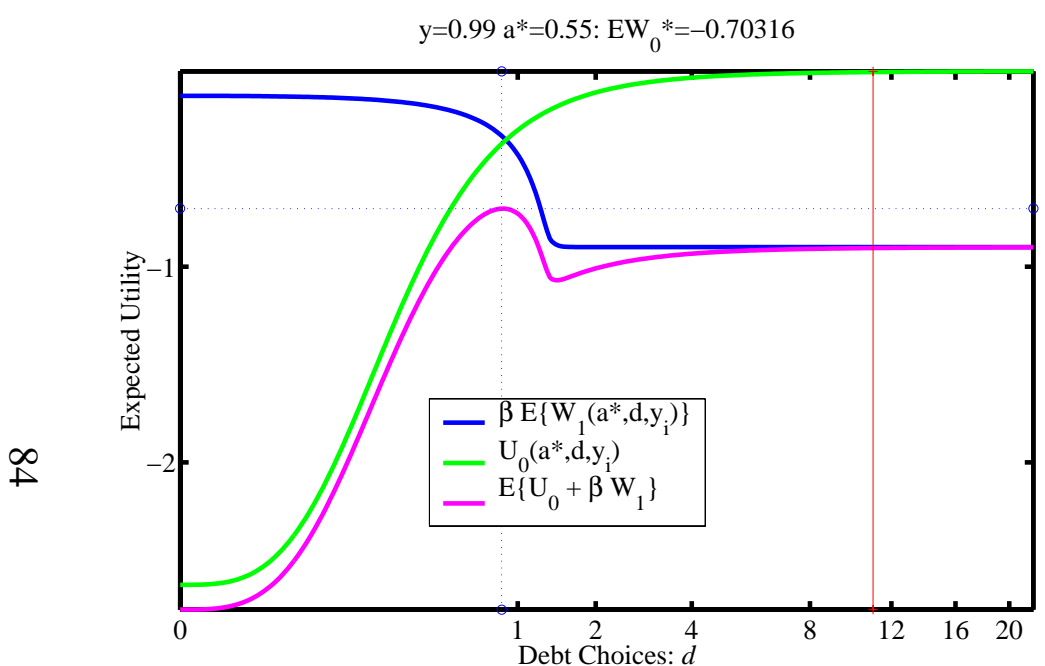

(a) Interior optimum $a, d$

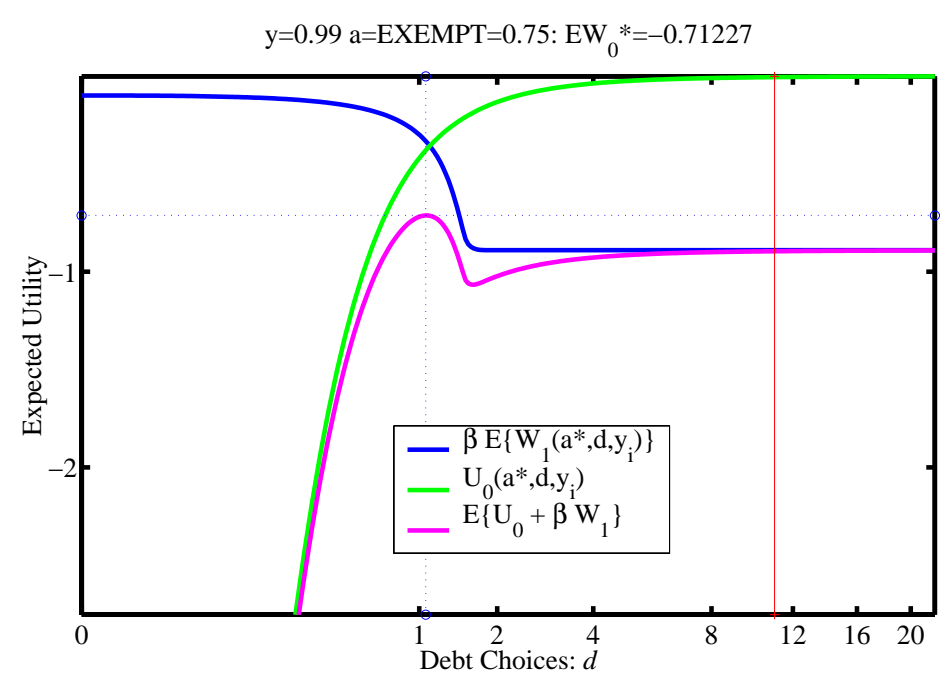

(b) Maximal borrowing strategy: $a=X, d \rightarrow \infty$

NOTE. Figures give examples of the utility in the first (the green lines) and second (the blue lines) periods of life as a function of the quantity of borrowing in the first period of life; the present discounted value is given by the magenta lines. Panel (a) displays utilities as a function of debt choices when assets are set to their interior optimal level; panel (b) when assets are set to the exemption level. In neither case does the maximal borrowing strategy dominate the interior optimum; further, the peak of the bottom panel is below the peak of the top panel. 
FIGURE 2: Income shocks

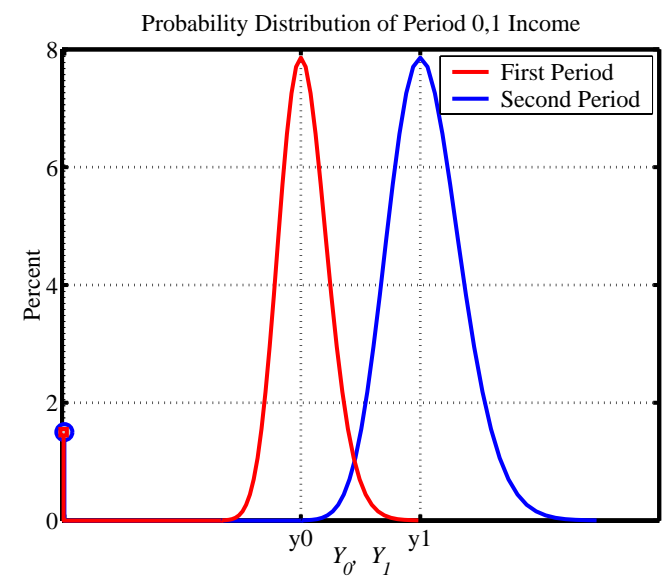

FIGURE 3: Lender profits

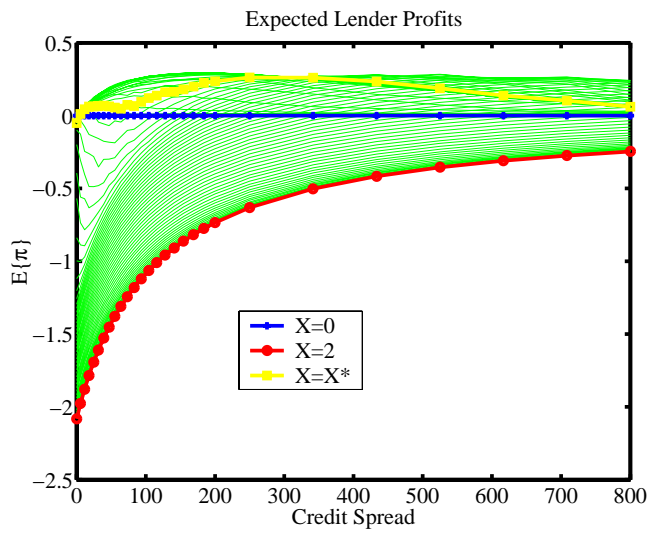

NoTE. Figures plot the distribution of period 0 and period 1 incomes (note the mass points at a low level) and lenders' profit schedules as functions of their interest rates (in basis points) under different bankruptcy law asset exemptions. Note that at the highest exemption level $(X=1)$ it is impossible for the lender to make positive profits; also, sometimes multiple equilibrium interest rates results in zero profits. 
FIGURE 4: Social welfare

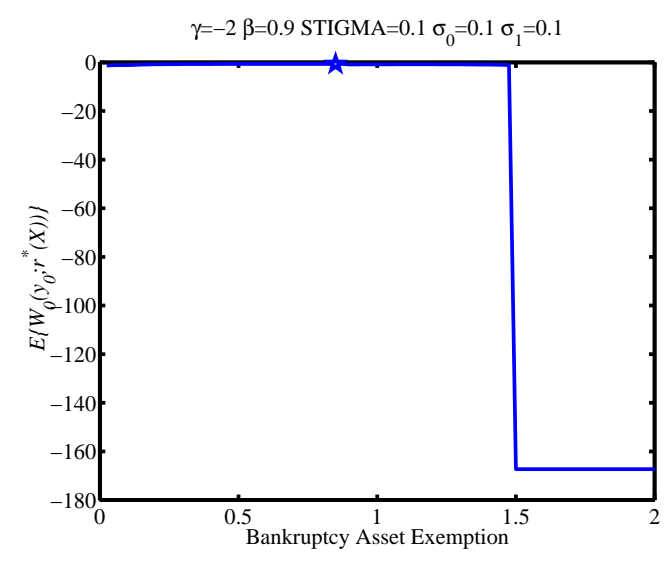

FIGURE 5: Lender interest rates

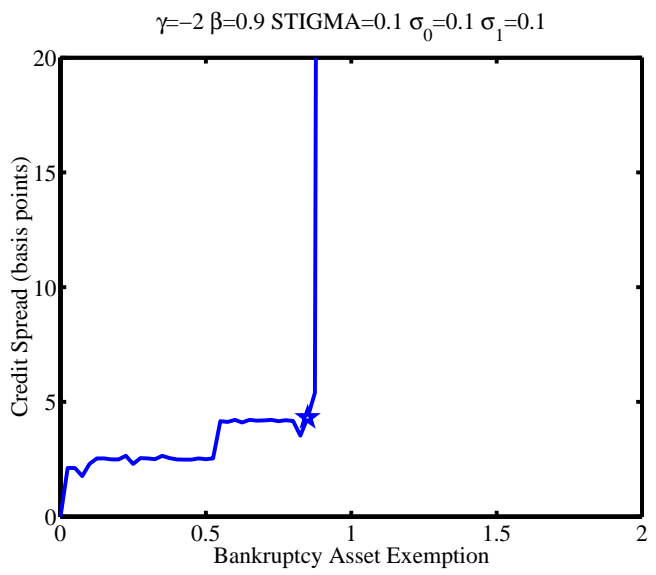

NoTE. Figures gives the expected present discounted value of all agents in the economy and equilibrium interest rates on unsecured debt under different levels of asset exemptions. The bankruptcy exemption associated with the global maximum social welfare is marked with a star. 
FIGURE 6: Model results

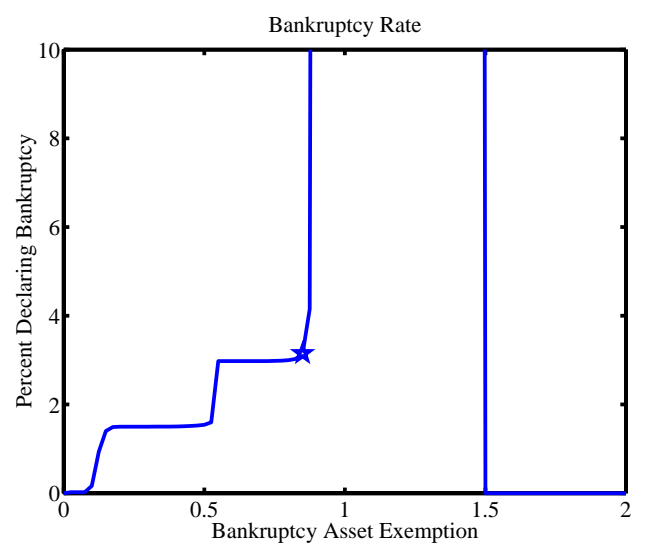

(a) Bankruptcy rates and exemptions

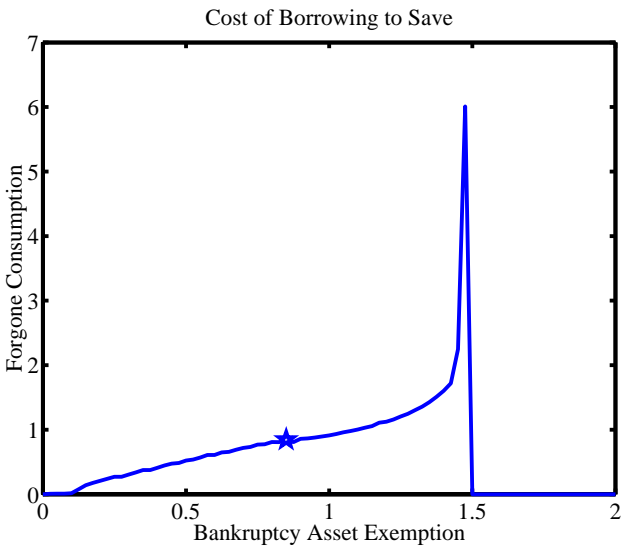

(b) Borrowing to save

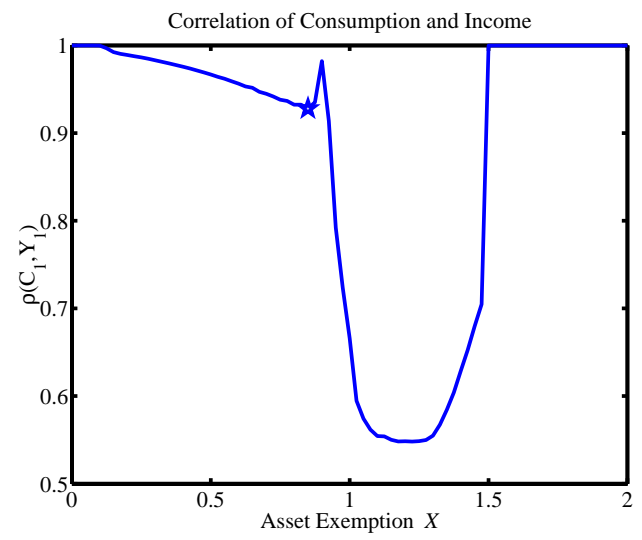

(c) Olney effect

NOTE. The three panels of the figures show the theoretical foundation that we investigate empirically. Panel (a) shows the aggregate bankruptcy rate as a function of the asset exemption, panel (b) shows the quantity of borrowing to save in the economy, measured in terms of forgone consumption and panel (c) shows the correlation of second period consumption and income, the so-called "Olney effect." In all cases, the exemption level associated with the global social welfare optimum is marked with a star. 
FIgURE 7: Cumulative distributions of debt and debt to income ratios

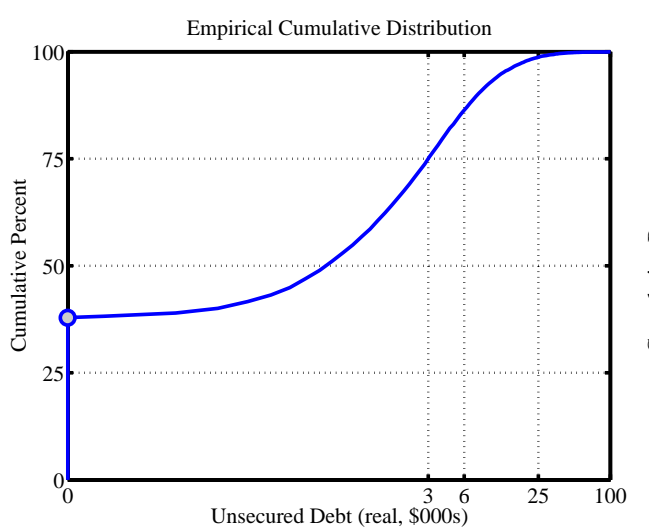

(a) Unsecured debt, $d$.

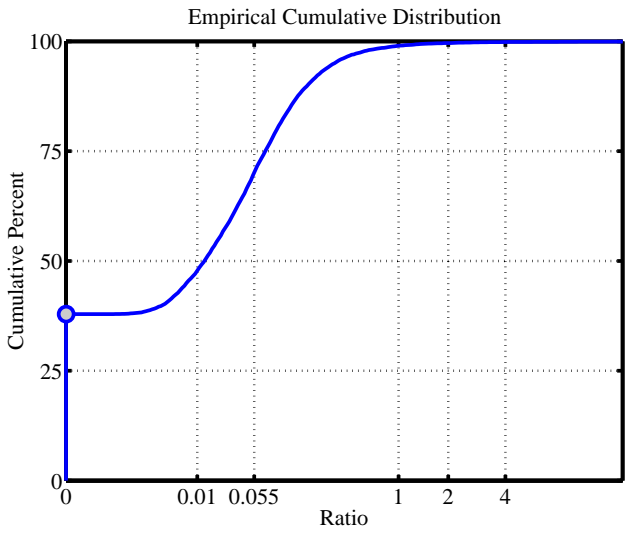

(b) Debt to actual income $d / y$.

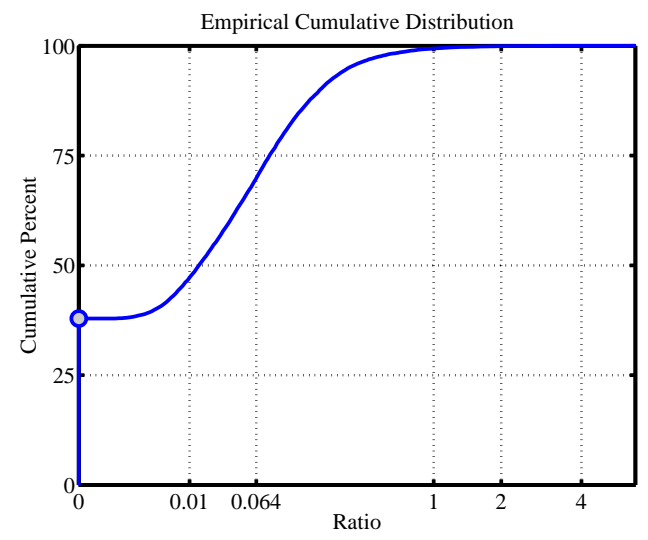

(c) Debt to potential income $d / \widehat{y}$.

Note. Figures give the empirical cumulative distribution of unsecured debt (panel a) in the CE, the ratio of unsecured debt to actual income (panel b), and the ratio of unsecured debt to potential income (panel c). About $37 \%$ of the CE sample report owing zero unsecured debt (indicated by the large grey dots). 
FIGURE 8: Distribution of Income Across Debt Measures

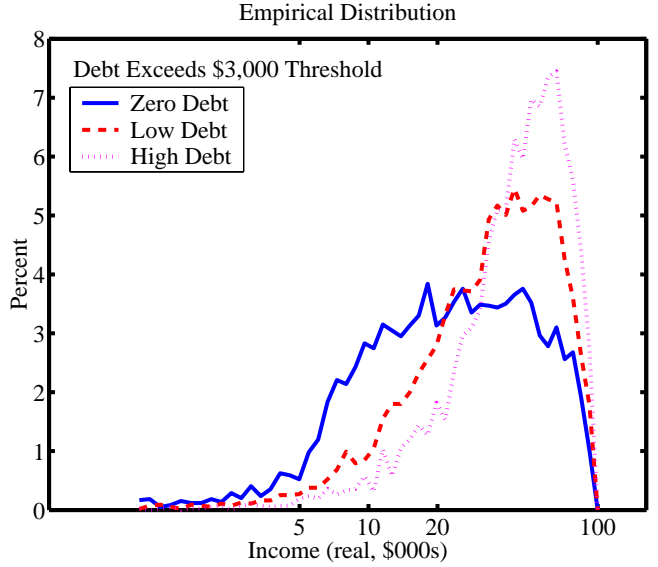

(a) $\$ 3,000$ Threshold

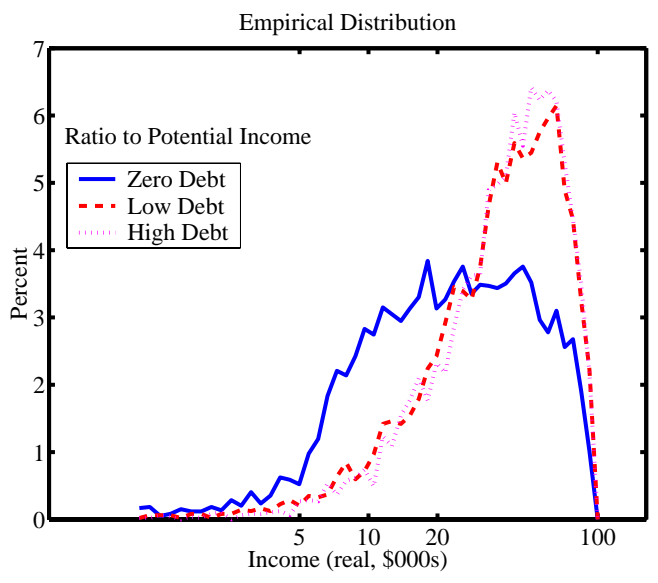

(c) Debt to potential income ratio

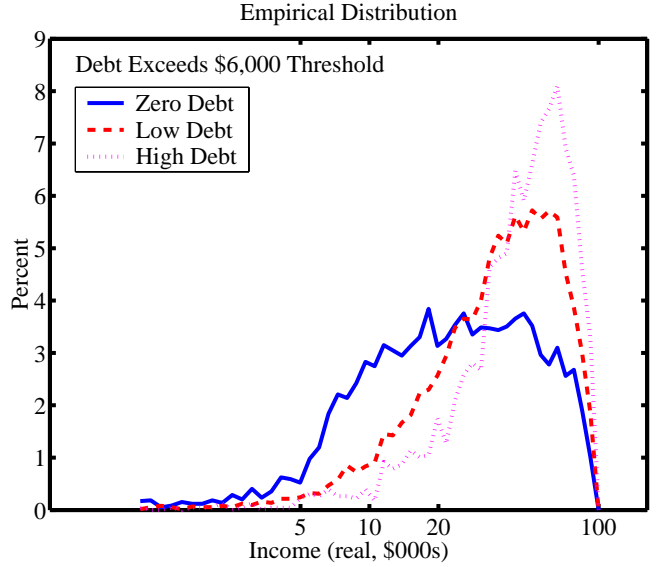

(b) $\$ 6,000$ Threshold

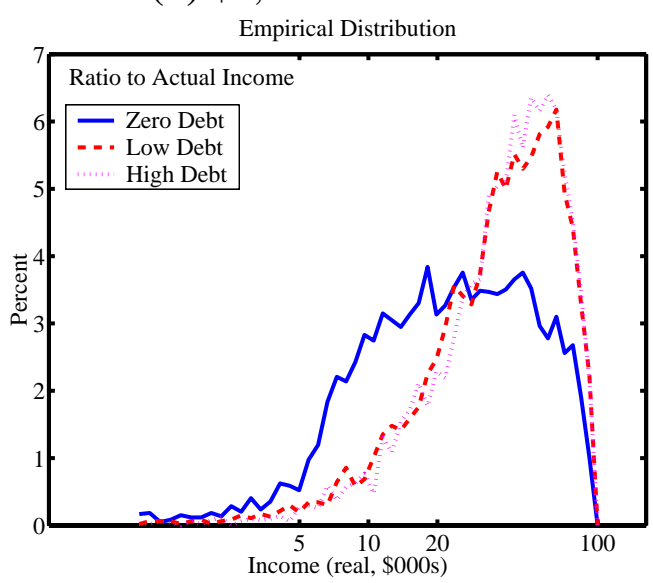

(d) Debt to actual income ratio

NOTE. Figure gives the distribution of real incomes among those with zero debt, low debt and high debt for four different definitions of high debt. Notice (1) That the income distribution of zero debt holders is relatively flat; and (2) Separating based on a threshold criterion produces two relatively dissimilar income distributions, while separating on a debt to income ratio criterion two more-similar income distributions. 


\section{FIGURE 9: Consumption and Income Shock Distributions}

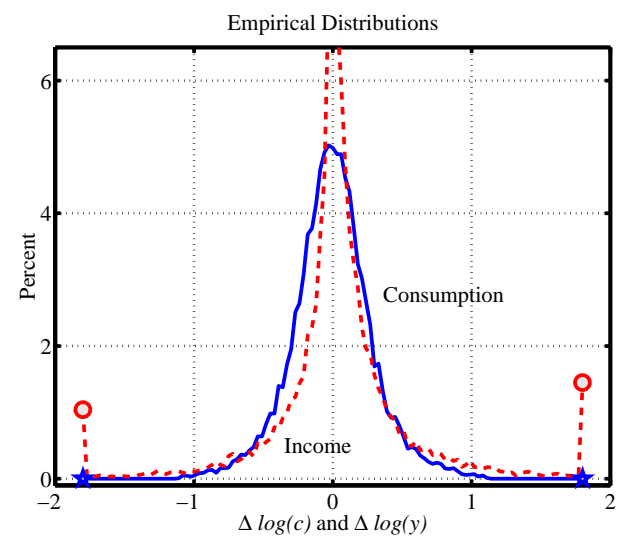

(a)

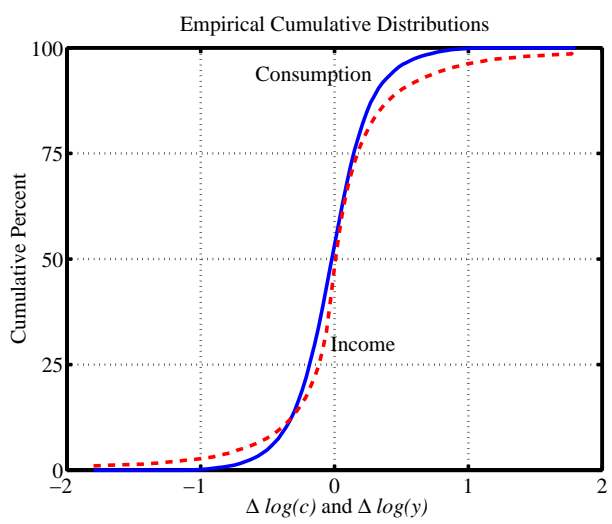

(b)

NoTE. Figures give the empirical pdf (panel a) and cdf (panel b) of the log differences in consumption and income. Note that the distribution of income differences features very fat tails (indicated by the grey dots) but also less central variation. Thus income shocks are either small or quite large. 